NBER WORKING PAPER SERIES

\title{
SURVEY MEASUREMENT OF PROBABILISTIC MACROECONOMIC EXPECTATIONS: PROGRESS AND PROMISE
}

\author{
Charles F. Manski \\ Working Paper 23418 \\ http://www.nber.org/papers/w23418 \\ NATIONAL BUREAU OF ECONOMIC RESEARCH \\ 1050 Massachusetts Avenue \\ Cambridge, MA 02138 \\ May 2017
}

This research was supported in part by National Science Foundation grant SES-1129475. I am grateful for comments on earlier drafts from Nicholas Bloom, Martin Eichenbaum, Pamela Giustinelli, Lawrence Hazelrigg, Jonathan Parker, Wilbert van der Klaauw, and Joachim Winter. The views expressed herein are those of the author and do not necessarily reflect the views of the National Bureau of Economic Research.

NBER working papers are circulated for discussion and comment purposes. They have not been peer-reviewed or been subject to the review by the NBER Board of Directors that accompanies official NBER publications.

(C) 2017 by Charles F. Manski. All rights reserved. Short sections of text, not to exceed two paragraphs, may be quoted without explicit permission provided that full credit, including () notice, is given to the source. 
Survey Measurement of Probabilistic Macroeconomic Expectations: Progress and Promise Charles F. Manski

NBER Working Paper No. 23418

May 2017

JEL No. D84,E03,E66

\begin{abstract}
$\underline{\text { ABSTRACT }}$
Economists commonly suppose that persons have probabilistic expectations for uncertain events, yet empirical research measuring expectations was long rare. The inhibition against collection of expectations data has gradually lessened, generating a substantial body of recent evidence on the expectations of broad populations. This paper first summarizes the history leading to development of the modern literature and overviews its main concerns. I then describe research on three subjects that should be of direct concern to macroeconomists: expectations of equity returns, inflation expectations, and professional macroeconomic forecasters. I also describe work that questions the assumption that persons have well-defined probabilistic expectations and communicate them accurately in surveys. Finally, I consider the evolution of thinking about expectations formation in macroeconomic policy analysis. I favorably observe the increasing willingness of theorists to study alternatives to rational expectations assumptions, but I express concern that models of expectations formation will proliferate in the absence of empirical research to discipline thinking. To make progress, I urge measurement and analysis of the revisions to expectations that agents make following occurrence of unanticipated shocks.
\end{abstract}

\author{
Charles F. Manski \\ Department of Economics \\ Northwestern University \\ 2001 Sheridan Road \\ Evanston, IL 60208 \\ and NBER \\ cfmanski@northwestern.edu
}




\section{Contents}

\section{Introduction}

2. Development of Research Measuring Probabilistic Expectations

2.1. Economic Research on Choice under Uncertainty, without Expectations Data

2.1.1. Assumptions on Income Expectations

2.1.2. The Credibility of Rational Expectations Assumptions

2.2. Survey Measurement of Expectations

2.2.1. Attitudinal Research

2.2.2. Consumer Confidence Surveys

2.2.3. Measurement of Probabilistic Expectations in Cognitive Psychology

2.2.4. Measurement of Probabilistic Expectations in Economics

3. Concerns of the Modern Microeconomic Literature

3.1. Descriptive Analysis of the Data

3.1.1. Measuring Perceptions of Job Insecurity

3.2. Analysis of the Accuracy of Elicited Expectations

3.3. Using Choice Expectations to Predict Choice Behavior

3.4. Using Expectations and Choice Data to Estimate Econometric Decision Models

3.5. Analysis of Expectations Formation

4. Expectations of Equity Returns

4.1. Competing Perspectives on Heterogeneity of Expectations

4.2. Elicitation of Probabilistic Expectations

4.3. Expectations and Stock Holdings

5. Inflation Expectations

5.1. Measurement of Inflation Expectations in the Survey of Consumer Expectations

5.1.1. Asking about "Inflation" or about "Prices in General"

5.1.2. Probability Elicitation in the SCE

6. Expectations of Professional Macroeconomic Forecasters

6.1. Point Predictions Derived from Probabilistic Forecasts

6.2. Empirical Research on Probabilistic Expectations

6.3. Communicating Uncertainty and Disagreement in the Macroeconomic Forecasts of Central Banks

7. Probabilistic Thinking and Communication

7.1. Rounding

7.2. Ambiguity

7.3. Confounding Beliefs and Preferences

7.3.1. Evidence in Research Measuring Probabilistic Expectations

8. Looking Ahead: Studying Expectations Formation to Inform Macro Policy Analysis

8.1. The Dynamics of Macroeconomic Perspectives on Expectations Formation

8.2. The Potential Contribution of Expectations Measurement 


\section{Introduction}

Economists commonly suppose that persons have probabilistic expectations for uncertain events. There are good reasons to think that expectations may vary across persons. Persons forecasting micro events may face different idiosyncratic circumstances. Persons forecasting macroeconomic events may have different knowledge of the state of the economy or different beliefs about how the economy functions.

One might anticipate that economists would regularly use surveys to measure heterogeneous probabilistic expectations. However, collection of expectations data was long rare. Economists have tended to be skeptical of subjective statements. Students have been taught that a good economist believes what people do, not what they say. This perspective inhibited collection of data on expectations. Lacking data, economists have assumed that persons hold particular expectations or have sought to infer expectations from observed choice behavior.

Since about 1990, the historical inhibition of economists against collection of expectations data has progressively lessened, generating a substantial body of modern empirical evidence on the probabilistic expectations of broad populations. Collection and analysis of these data has been performed mainly by microeconomists and has consequentially been motivated primarily by a desire to inform microeconomic research. An early review article by Manski (2004) described the emergence of this field of empirical study and summarized a range of initial applications. More recent review articles by Hurd (2009), Armantier et al. (2013), Delavande (2014), and Schotter and Trevino (2014) have respectively focused on work measuring expectations of older persons, inflation, populations in developing countries, and subjects making decisions under uncertainty in lab experiments.

The present article begins by describing the history leading to development of the modern literature measuring the probabilistic expectations of broad populations (Section 2). I first recall the longstanding economic practice of revealed preference analysis, which has studied choice under uncertainty using 
assumptions about the expectations that persons hold, rather than expectations data. I particularly critique conventional assumptions asserting that persons have rational expectations (RE). I then summarize multiple literatures that have collected various types of expectations data. These include the use of questions seeking verbal responses in attitudinal research and consumer confidence surveys and measurement of probabilistic expectations in cognitive psychology and, more recently, in economics.

Section 3 overviews the main concerns of the modern economic literature collecting and analyzing data measuring probabilistic expectations. The research of the 1990s and early 2000s performed considerable descriptive data analysis, aiming to evaluate how persons respond to the questions posed and to assess the accuracy of elicited expectations. More recent work has increasingly used expectations data to predict choice behavior and to replace expectations assumptions when estimating microeconometric models of decision making under uncertainty. There also has been research aiming to understand processes of expectations formation.

I then describe research on three subjects that should be of direct concern to macroeconomists: expectations of equity returns (Section 4), inflation expectations (Section 5), and professional macroeconomic forecasters (Section 6). On the first subject, I first review competing perspectives in finance theory on the existence and importance of heterogeneity of expectations. I then discuss a body of work that elicits probabilistic expectations of equity returns, describes heterogeneity in expectations, and attempts to draw inferences about processes of expectations formation. Some of this work relates elicited expectations to household decisions to include stocks in their portfolios.

Considering inflation expectations, I first mention efforts to measure such expectations nonprobabilistically and then focus attention on the measurement of probabilistic expectations in the recently initiated Survey of Consumer Expectations. I contrast the probabilistic question format used in this survey with the one seeking a point prediction in the venerable Michigan Survey of Consumers. Beyond its specific concern with inflation expectations, this section illustrates the general importance of careful attention to 
question wording when designing survey questions on expectations and analyzing the responses.

Section 6 turns from the expectations of broad populations to those of professional macroeconomic forecasters. I first critique the traditional practice of asking forecasters to make point predictions of future macroeconomic events. While the discussion focuses on macroeconomic forecasting, the cautions I express about interpretation of point predictions apply when asking persons to forecast any uncertain event. I next describe empirical research analyzing the probabilistic expectations data collected in the Survey of Professional Forecasters. Finally, I discuss the practice of central banks in communicating uncertainty and disagreement in their macroeconomic forecasts.

Sections 3 through 6 maintain the assumption that persons have well-defined probabilistic expectations and communicate them accurately in surveys. Section 7 questions this assumption in various ways. I first call attention to the prevalence of rounding of probabilistic expectations responses and I summarize research aiming to characterize the extent to which different persons round. I then discuss empirical research on ambiguity (aka Knightian uncertainty) that seeks to elicit expectations that do not have the full structure of precise probability distributions. I also consider the possibility that persons may confound beliefs and preferences, in contrast to the standard assumption of decision theory that beliefs and preferences are distinct concepts.

Section 8 offers my thoughts on the evolution of thinking about expectations formation in macroeconomic policy analysis. I strongly endorse the attention called to expectations formation by Lucas (1976), but not the Lucas assertion that researchers should always assume agents have rational expectations. I favorably observe the increasing willingness of macroeconomic theorists to pose and study alternatives to the RE assumption, but I worry that models of expectations formation will proliferate endlessly in the absence of empirical research to discipline thinking. I caution that little about expectations formation can be learned from empirical research analyzing choice data alone. To make progress, I urge measurement and analysis of the revisions to expectations that agents make following occurrence of unanticipated shocks. 
I hope that this paper will be useful to readers of two types. One type are persons who are already undertaking or contemplating initiation of empirical research on expectations. I expect that such persons will want to read the paper more or less in order from beginning to end. A second type are persons who have not yet thought about performing their own empirical research but who are concerned about the assumptions on expectations formation used in macroeconomic policy analysis. Some such persons may want to first do a light read of Section 2 through 7, next focus on Section 8, and then reread parts of Sections 2 through 7 in more depth as it suits them.

\section{Development of Research Measuring Probabilistic Expectations}

2.1. Economic Research on Choice under Uncertainty, without Expectations Data

Motivation for economists to measure expectations stems from the longstanding objective of the profession to understand and predict choice under uncertainty. When economists study choice under uncertainty, it has been standard to suppose that utility functions express preferences over outcomes, probabilistic expectations express beliefs about uncertain events, and persons choose actions to maximize expected utility. It has been standard to seek to infer preferences and beliefs from data on observed choices. Empirical research of this type is called revealed-preference analysis, the name given by Samuelson (1938, 1948) in his pioneering work studying choice in deterministic settings.

When considering choice under uncertainty, the actual task of revealed-preference analysis is to learn both preferences and beliefs, not preferences alone. Researchers often confront a severe identification problem: an observed choice made by an agent maximizing expected utility may be consistent with many plausible utility functions and subjective probability distributions. To achieve identification, economists 
commonly combine choice data with strong assumptions about expectations formation and the structure of preferences.

\subsubsection{Assumptions on Income Expectations}

To illustrate, consider the assumptions made about personal income expectations in studies of precautionary savings. Economists have regularly assumed that persons have rational expectations regarding future income. That is, they know the actual stochastic process generating their income streams conditional on available private information.

Economists often assume that persons use knowledge of their own past incomes to forecast their future incomes. Perhaps so, but how do persons form expectations of future income conditional on past income? The practice has been to specify the income process up to some parameters and use available data on income realizations to estimate the parameters. Yet researchers differ in their specifications of the stochastic process presumed to generate income. The literature has generated competing models, with no clear way of distinguishing among them in the absence of data measuring expectations. See, for example, Hall and Mishkin (1982), Skinner (1988), Zeldes (1989), Caballero (1990), and Carroll (1992).

\subsubsection{The Credibility of Rational Expectations Assumptions}

Whether considering income or other expectations, it has been standard practice for economists to assume that decision makers have specified expectations and to suppose that these expectations are "rational" in the sense of being objectively correct conditional on specified information. Imposing such assumptions is enticing, because it reduces the task of empirical analysis of choice data to inference on preferences alone. Researchers may also find it self-gratifying to specify their own visions of how the economy works and to assume that the persons who populate the economy share their vision.

Unfortunately, the RE assumptions made in economic research may have little credibility. Early 
on, Friedman and Savage (1948) argued for the realism of RE by invoking the metaphor of an expert pool player who is able to accurately predict the direction of travel of a billiard ball without knowledge of the relevant physics. However, a pool player operates in a stable environment with ample opportunity for learning-by-doing. RE is far less plausible in realistic economic settings that lack this stability and possibility to learn. Pesaran (1987) phrased the issue well thirty years ago, writing that the RE hypothesis (page 2) "is based on extreme assumptions and cannot be maintained outside the tranquility of a long-period steady state." More recent discussions appear in Manski (2004) and Gennaioli, Ma, and Schleifer (2016).

For my part, I have repeatedly stressed that economists and ordinary persons face similar inferential problems-identification and induction from finite samples-when they attempt to make sense of the world. Whoever one is, consumer or firm or empirical economist, the inferences that one can logically draw are determined by the available data and the assumptions that one brings to bear. Empirical economists seldom are able to completely learn objective probability distributions of interest, and they often cannot learn much at all. I therefore find it hopelessly optimistic to suppose that, as a rule, the expectations of ordinary persons are even approximately rational.

To illustrate, consider schooling choice, which lacks the stable environment and opportunity for learning-by-doing of the pool game. In Manski (1993), I observed that youth forming personal expectations for the returns to schooling confront inferential problems similar to those that labor economists face when they study the returns to schooling. The research literature in labor economics exhibits much debate on the credibility of assumptions and many disagreements about findings. If experts disagree on the returns to schooling, is it plausible that youth have rational expectations? I think not.

I stressed that decision makers and empirical economists alike must contend with the logical unobservability of counterfactual outcomes. Much as economists attempt to infer the returns to schooling from data on realized schooling choices and outcomes, youth may attempt to learn through observation of the experiences of family, friends, and others who have made their own past schooling decisions. However, 
youth cannot observe the outcomes that these people would have experienced had they made other decisions.

I used a simple human capital model to show that how youth forecast counterfactual outcomes is consequential. I showed specifically that interpretation of data on schooling choices can depend critically on how youth use ability information to form expectations of the returns to schooling. A particularly striking finding was that, if youth do not possess private information on their ability, a researcher who assumes that they condition expectations on ability may mistakenly conclude from observed choices that youth are unconcerned with the returns to schooling.

I would caution readers who are fond of RE assumptions against thinking that schooling choice is an unusual case. To the contrary, it is the pool game that is atypical of the environments that economic agents face.

\subsection{Survey Elicitation of Expectations}

Concern with the credibility of the expectations assumptions made in economic research motivates the idea of asking persons about their expectations. Elicitation of expectations in surveys has a long history in the social sciences, predating measurement of probabilistic expectations by economists. In this section I first briefly describe this precedent research, critiquing the verbal questions posed in attitudinal research and discussing elicitation of probabilistic expectations in cognitive psychology. I then turn to the development of the economic literature.

\subsubsection{Attitudinal Research}

Attitudinal researchers, primarily sociologists and social psychologists, have long used verbal questions to measure expectations. Respondents may be asked to report whether they "think" or "expect" 
that a specified event will occur. Sometimes they are asked to report the strength of this belief by reporting whether it is "very likely," "fairly likely," "not too likely," or "not at all likely" that the event will occur. A prominent example is this question on job loss in the General Social Survey, a pivotal sociological survey in the United States (Davis and Smith, 1994):

General Social Survey Job-Loss Question: "Thinking about the next twelve months, how likely do you think it is that you will lose your job or be laid off? very likely, fairly likely, not too likely, or not at all likely?"

This question illustrates a persistent problem that researchers face in interpreting verbal expectations data-assessment of the interpersonal comparability of responses. Do different respondents to the General Social Survey interpret the phrases "very likely, fairly likely, not too likely, or not at all likely" in the same way? Cognitive research does not give reason to think that responses should be or are comparable. Indeed, the available empirical evidence indicates that interpretation of verbal expectations questions varies substantially between persons (Lichtenstein and Newman, 1967; Beyth-Marom, 1982; Wallsten et al., 1986). One may also question whether responses are intra-personally comparable; that is, a given respondent may interpret verbal phrases in different ways when asked about different events.

A second persistent problem is that the coarseness of the response options limits the information contained in the responses to traditional attitudinal questions. Consider, for example, the fertility question asked female respondents in the annual June Supplement to the Current Population Survey (U. S. Census Bureau, 1988):

Current Population Survey Fertility Question: "Looking ahead, do you expect to have any (more) children? Yes No Uncertain"

The three response options do not enable respondents to express the degree of uncertainty they perceive 
about their future childbearing.

\subsubsection{Consumer Confidence Surveys}

A form of attitudinal research long familiar to macroeconomists is the periodic measurement of consumer confidence (or sentiment) in surveys. The monthly Michigan Index of Consumer Sentiment (ICS) is reported regularly in the media, along with commentary on its significance for the economy. So is another measure, the Consumer Confidence Index issued monthly by the Conference Board. The ICS was developed in the late 1940s by George Katona and colleagues at the Survey Research Center of the University of Michigan (Curtin, 1982). The Conference Board index has been issued since 1967 (Linden, 1982).

Both indices aggregate responses to verbal expectations questions. The ICS is partially based on the coded responses to these questions:

"Now turning to business conditions in the country as a whole--do you think that during the next 12 months we'll have good times financially, or bad times, or what?

Good times; Good with qualifications; Pro-con; Bad with qualifications; Bad times"

"Now looking ahead--do you think that a year from now you (and your family living there) will be better off financially, or worse off, or just about the same as now?

Will be better off; Same; Will be worse off"

These questions exemplify the problem that researchers face in interpreting verbal expectations data. How do respondents to the Michigan survey interpret the phrases "business conditions" and "good times financially?" How do respondents answer the questions when they are not certain what will happen in the year ahead? 
The idea underlying development of the ICS was that the responses to these and other questions may be useful as "leading indicators" in predicting aggregate consumption and other macroeconomic variables. This proposition was controversial, and the Federal Reserve Board, which funded the Michigan data collection, appointed a committee to assess the value of the SRC data. The Federal Reserve Consultant Committee on Consumer Survey Statistics (1955) issued findings that questioned the predictive power of the Michigan data. The negative findings of the Committee were challenged by Michigan researchers, notably Katona (1957). A contentious conference followed (National Bureau of Economic Research, 1960). Then Juster (1964) reported an intensive study, drawing largely negative conclusions, on the predictive usefulness of verbal approaches to elicitation of consumer expectations. By the mid-1960s, opinion among mainstream economists was firmly negative. However, Michigan continued to perform its consumer survey and to publish aggregated findings in its ICS. Moreover, the Conference Board initiated its own survey and index.

For many years, analyses of the Michigan and Conference Board data mainly examined the time series of aggregate summary statistics, such as the ICS. More recently, some researchers have examined and sought to interpret the underlying microdata. See, for example, Souleles (2004), Piazzesi and Schneider (2009), and Armantier et al. (2013).

\subsubsection{Measurement of Probabilistic Expectations in Cognitive Psychology}

If persons can express their expectations in probabilistic form, elicitation of subjective probability distributions should have compelling advantages relative to verbal questioning. Perhaps the most basic attraction is that probability provides a well-defined absolute numerical scale for responses; hence, there is reason to think that responses may be interpersonally and intrapersonally comparable. Another attraction is that empirical assessment of the internal consistency of respondents' expectations is possible. A researcher can use the algebra of probability (Bayes Theorem, the Law of Total Probability, etc.) to examine 
the internal consistency of a respondent's expectations about different events.

When probability has a frequentist interpretation, a researcher can compare elicited subjective probabilities with known event frequencies and reach conclusions about the correspondence between subjective beliefs and frequentist realities. Such calibration studies have a long history in cognitive psychology. Lichtenstein, Fischhoff, and Phillips (1982) review findings from 1906 on, and McClelland and Bolger (1994) update the review with findings from 1980 through 1994. Whereas the older studies mostly examined the accuracy of experts (e. g., weather forecasters' reported probabilities of precipitation), much recent research analyzes the expectations of non-experts, especially students in a cognitive laboratory.

Within cognitive psychology, there has been controversy about the way in which humans internally represent their beliefs, and their ability and willingness to express their beliefs as numerical probabilities. Koriat, Lichtenstein, and Fischhoff (1980) and Ferrell and McGoey (1980) posed models in which individuals may have some difficulty expressing beliefs as numerical probabilities, but nevertheless concluded that elicitation of numerical subjective probabilities is feasible. However, Zimmer $(1983,1984)$ argued that humans process information using verbal rather than numerical modes of thinking, and he concluded that expectations should be elicited in verbal rather than numerical forms.

Erev and Cohen (1990) and Wallsten et al. (1993) have reported that a majority of respondents prefer to communicate their own beliefs verbally and to receive the beliefs of others in the form of numerical probabilities. This asymmetry is intriguing but only marginally relevant to the design of expectations questions. The relevant question is not what communication mode respondents prefer to use, but rather what modes they are willing and able to use. Wallsten et al. (1993) report that virtually all of their respondents were willing to communicate their beliefs numerically, should the situation warrant it.

Another controversy concerns how persons process objective probabilistic information. In an influential article, Tversky and Kahneman (1974) summarized some experiments in which subjects were presented with statistics of various forms and were asked for probabilistic predictions of specified events. 
They interpreted the findings as showing that persons tend to use certain heuristic rules to process data, rather than Bayes Theorem.

To the extent that the Tversky and Kahneman experiments shed light on expectations formation in real life, they cast doubt on the assumption of rational expectations, not on the representation of expectations through subjective probability distributions. Indeed, Tversky and Kahneman argued for the psychological realism of subjective probabilities. Considering the propensity of axiomatic decision theorists to view subjective probabilities as constructs that may be inferred from choices, they wrote (p.1130):

"It should perhaps be noted that, while subjective probabilities can sometimes be inferred from preferences among bets, they are normally not formed in this fashion. A person bets on team A rather than on team B because he believes that team $\mathrm{A}$ is more likely to win; he does not infer this belief from his betting preferences. Thus, in reality, subjective probabilities determine preferences among bets and are not derived from them, as in the axiomatic theory of rational decision."

The controversy about the Tversky-Kahneman experiments concerns the degree to which they do shed light on subjects' use of Bayes Theorem to process data. Gigerenzer (1991) argued that the reported empirical regularities result not from respondents' use of heuristics but from the manner in which statistical information was presented to them. Here and elsewhere (e.g., Hoffrage et al., 2000), Gigerenzer and his colleagues have reported experimental evidence indicating that respondents perform much better in applying probability theory when statistics are presented in the form of natural frequencies rather than objective probabilities (e. g., "30 out of 10,000 cases," rather than "0.3 percent of cases.")

\subsubsection{Measurement of Probabilistic Expectations in Economics}

Among economists, the idea that survey measurement of probabilistic expectations might improve on the verbal approaches of attitudinal research appears to have originated with Juster (1966). Considering the case in which the behavior of interest is a binary purchase decision (buy or not buy), Juster considered 
how responses to traditional yes/no buying intentions questions should properly be interpreted. He wrote (Juster, 1966, page 664): “Consumers reporting that they 'intend to buy A within X months' can be thought of as saying that the probability of their purchasing A within X months is high enough so that some form of 'yes' answer is more accurate than a 'no' answer."

Thus, Juster hypothesized that a consumer facing a yes/no intentions question responds as would a decision maker asked to make a best point prediction of a future random event. Working from this hypothesis, he concluded that it would be more informative to ask consumers for their purchase probabilities than for their buying intentions. In particular, he proposed questions that associate verbal expressions of likelihood with numerical probabilities to elicit purchase expectations for automobiles and other household appliances:

Juster Purchase Probability Questions: "Taking everything into account, what are the prospects that some member of your family will buy a __ sometime during the next __ months, between now and _ ?

Certainly, Practically Certain (99 in 100); Almost Sure (9 in 10); Very Probably (8 in 10); Probably (7 in 10); Good Possibility (6 in 10); Fairly Good Possibility (5 in 10); Fair Possibility (4 in 10); Some Possibility (3 in 10); Slight Possibility (2 in 10); Very Slight Possibility (1 in 10); No Chance, Almost No Chance (1 in 100)."

He went on to collect data and concluded that elicited purchase probabilities are better predictors of subsequent individual purchase behavior than are yes/no intentions data.

Market researchers were attracted to Juster's proposal (e. g., Morrison, 1979). The idea that expectations might be elicited probabilistically from survey respondents did not, however, draw the immediate attention of economists. When Juster's article was published, economists were preaching that empirical research on decision making should be based on choice data alone. A quarter century passed before economists began to systematically collect and analyze probabilistic expectations data in broad populations. 
The conventional economic wisdom finally unraveled in the 1990s. Numerous large-scale surveys now use probabilistic formats to elicit expectations, and a new field of empirical research has emerged. Subjects that have drawn attention include expectations of risks that a person faces (job loss, crime victimization, mortality), future personal income (including returns to schooling and pensions), choices that persons make (durable purchases, voting choices), and macroeconomic events (equity returns, inflation). The modern economic literature measuring probabilistic expectations has developed mainly in isolation from the body of related research in psychology, but there have been occasional notable collaborations of economists and psychologists; see Bruine de Bruin and Fischhoff (2017).

The standard question format has been to seek a response on a $[0,100]$ percent-chance scale. Thus, the typical question inquiring about a binary event has the structure "What do you think is the percentchance that (a specified event) will occur?"

When inquiring about a continuous random variable, the same format is used to elicit points on the distribution function or the probability that the event will lie in some interval. Thus, a question may have the form "What do you think is the percent chance that (a specified random variable) will have a value less than or equal to $(\mathrm{X})$ " or "What do you think is the percent chance that (a specified random variable) will have a value between (X0) and (X1)?" It is common to ask multiple such questions, varying the threshold $\mathrm{X}$ or the interval $(\mathrm{X} 0, \mathrm{X} 1)$. The resulting data on the subjective distribution may be analyzed nonparametrically or a specified parametric distribution may be fit to the data. See, for example, Dominitz and Manski (1997a) and Engelberg, Manski, and Williams (2009).

Major repeated surveys in the United States with modules eliciting probabilistic expectations include the Health and Retirement Study (HRS) since 1992 (Juster and Suzman, 1995; Hurd and McGarry, 1995; Hurd, 2009), the Survey of Economic Expectations (SEE) from 1993 to 2002 (Dominitz and Manski, 1997a, 1997b), the 1997 cohort of the National Longitudinal Survey of Youth (NLSY97) since 1997 (Fischhoff et al., 2000; Dominitz, Manski, and Fischhoff, 2001), the American Life Panel (ALP) since 2006 
(Gutsche et al., 2014), and the Survey of Consumer Expectations (SCE) since 2013 (Armantier et al., 2013, 2016). Further major repeated surveys worldwide include the Bank of Italy Survey of Household Income and Wealth since 1989 (Guiso, Jappelli, and Terlizzese, 1992; Guiso, Jappelli, and Pistaferri, 2002), analogs of the HRS in many nations, and an analog of the SCE in Canada (Gosselin and Kahn, 2015). There also have been many one-time surveys undertaken to provide data for particular research projects.

While there has been an explosion of survey research measuring the probabilistic expectations of households, there exists no similarly large body of research measuring and analyzing the expectations of firms. An early survey that did collect such data was the 1993 Italian Survey of Investment in Manufacturing; see Guiso and Parigi (1999). However, surveys of firm expectations have in the past and mainly continue to pose questions seeking verbal responses or point predictions; see Bachman and Elstner (2015) and the literature cited there.

Regular collection of data on probabilistic expectations of firms is beginning to occur. Two examples are the recent fielding by the Federal Reserve Bank of Atlanta and the U.S. Census Bureau of periodic surveys asking senior managers in firms to provide probabilistic expectations on topics including future product shipments, capital expenditures, employment, and expenditures on materials; see Federal Reserve Bank of Atlanta (2017) and U.S. Census Bureau (2016). I have been made aware that similar survey efforts are now in progress in the United States and elsewhere (personal communication from Nicholas Bloom.)

\section{Concerns of the Modern Microeconomic Literature}

The objective of the modern economic literature measuring probabilistic expectations is to shed light on the beliefs that persons hold regarding future events and thereby to help understand and predict 
their choice behavior. To achieve this, the economists who design survey questions and analyze responses also perform research that aims to learn how respondents interpret the questions posed and to improve question design, so as to enhance the usefulness of the data. In this section I describe the types of research that have been performed.

\subsection{Descriptive Analysis of the Data}

Much of the research undertaken in the 1990s and early 2000s sought to answer basic empirical questions, including these:

(a) Are respondents willing and able to reply to questions seeking probabilistic responses? When I began to collect expectations data in the SEE in the early 1990s, I encountered considerable skepticism from researchers who asserted that probabilistic questioning would not "work." A common assertion was that respondents would either refuse to answer the questions or would only give the responses 0,50 , and 100 percent. It eventually became clear as data accumulated that this assertion was largely incorrect. Response rates to probabilistic expectations questions tend to be as high or higher than those to traditional attitudinal research questions. Respondents use the full expanse of the 0-100 percent-chance scale, typically rounding to multiples of 5 or $10 .^{1}$ See Section 7 for discussion of empirical evidence on rounding.

\footnotetext{
${ }^{1}$ To encourage full use of the percent-chance scale, it helps to familiarize respondents with the scale before commencing substantive questioning. For example, SEE used this introductory statement and opening question about the weather:

"Now I will ask you some questions about future, uncertain outcomes. In each case, try to think about the whole range of possible outcomes and think about how likely they are to occur during the next 12 months. In some of the questions, I will ask you about the percent chance of something happening. The percent chance must be a number from 0 to 100 . Numbers like 2 or 5 percent may be 'almost no chance,' 20 percent or so may mean 'not much chance,' a 45 or 55 percent chance may be a 'pretty even chance,' 80 percent or so may mean a 'very good chance,' and a 95 or 98 percent chance may be 'almost certain.' The percent chance can also be thought of as the number of chances out of 100 .
} 
(b) In the absence of incentives for honest revelation, do responses reveal the expectations that persons truly hold? ${ }^{2}$ Survey researchers cannot directly observe cognition, so this assertion is not answerable definitively. Nevertheless, it is possible to judge the degree to which persons give internally consistent and sensible responses to the questions posed, a criterion called face validity. It has been found that responses usually have high face validity when respondents are questioned about well-defined events relevant to their lives. See, for example, Dominitz and Manski (1997a, 1997b) and Bruine de Bruin et al. (2011). There are, however, occasional exceptions. A notable case was that teenagers interviewed in the NLSY97 were found to give highly inaccurate and sometimes logically inconsistent responses when asked to predict their chance of dying in the next year or the next several years; see Fischhoff et al. (2000).

One can also judge the degree to which elicited expectations relate sensibly to observed individual choices. Considerable evidence of this type has accumulated and it has mainly been positive. See the references cited below in Sections 3.3 and 3.4.

(c) What expectations do persons hold for their futures? Measurement of respondents' risk perceptions, income and employment expectations, and beliefs about other events has been substantively interesting to

Let's start with the weather where you live. What do you think is the percent chance (what are the chances out of 100) that it will rain tomorrow?"

${ }^{2}$ An absence of incentives is a common feature of all survey research, not a specific attribute of expectations questions. The literature on proper scoring rules develops incentive mechanisms for honest revelation of expectations concerning observable events (e.g., Shuford, Albert, and Massengill, 1966; Savage, 1971). These mechanisms usually aim to encourage honest revelation under the assumption that respondents maximize expected utility and are risk neutral. Proper scoring rules are regularly used in lab experiments eliciting probabilistic expectations (e. g., Nyarko and Schotter, 2002; Schotter and Trevino, 2014) but not in survey research. Application of a scoring rule requires the researcher to verify what events do and do not occur. Verification typically is not possible in survey settings. However, Amentier et al. (2015) analyzed whether inflation expectations collected in a survey are informative of decisions the same respondents subsequently make in an incentivized investment experiment. 
economists who heretofore have only been able to speculate about the expectations that people hold. Section 3.1.1 provides an illustration.

\subsubsection{Measuring Perceptions of Job Insecurity}

Research measuring worker perceptions of job insecurity illustrates the substantive contribution of descriptive analysis. Perceptions of job insecurity have been hypothesized to be determinants of economic outcomes ranging from wages and employment to consumption and savings. Meaningful empirical conclusions about the effects of job insecurity can be drawn only if the concept is defined clearly and measured appropriately. Writers often use the expression job insecurity without formal definition, but usage indicates that the expression is commonly intended to convey the chance that a worker will lose his present job and subsequently not obtain a position of comparable value.

To measure job insecurity, SEE posed these questions eliciting probabilistic expectations of job loss and job-search outcomes:

SEE Job-Loss Question: "I would like you to think about your employment prospects over the next 12 months. What do you think is the percent chance that you will lose your job during the next 12 months?"

SEE Search-Outcome Question: "If you were to lose your job during the next 12 months, what is the percent chance that the job you eventually find and accept would be at least as good as your current job, in terms of wages and benefits?"

Manski and Straub (2000) examined 3561 responses to these questions obtained from 1994 through

early 1998. The distribution of responses to the job-loss question was highly skewed, with most respondents perceiving little or no chance of job loss in the year ahead, but some viewing themselves as facing a moderate to high risk. The distribution of responses to the search-outcome question had a very different shape, being approximately symmetric and quite dispersed. 
The shape of the empirical distribution of search-outcome responses has an interesting interpretation in terms of the theory of job search. Standard models of job search with time-invariant reservation wages imply that the responses to the search-outcome question should be distributed uniformly on $[0,1]$. The empirical distribution of responses was reasonably close to uniform.

The responses to the job-loss and search-outcome questions can be combined to yield a composite measure of job insecurity. Let $\mathrm{L}$ denote the response to the job-loss question and $\mathrm{S}$ the response to the question on search outcome conditional on job loss. Then $\mathrm{L} \times(100-\mathrm{S}) / 100$ gives the percent chance that a worker will lose his job in the year ahead and subsequently not obtain a position of comparable economic value.

Examination of the cross-sectional and time-series variation across respondents in their perceptions of job insecurity yielded several interesting findings: (a) Expectations of job loss tended to decrease markedly with age, but so did expectations of a good outcome should job search become necessary. The net result was that the measure of composite job insecurity tended not to vary at all with age. (b) Subjective probabilities of job loss tended to decrease with schooling, and probabilities of good search outcomes tended to increase with schooling. Hence composite job insecurity tended to decrease with schooling. (c) Perceptions of job insecurity varied little by sex but substantially by race. The main differences were in expectations of job loss, with the subjective probabilities of blacks tending to be nearly double those of whites.

\subsection{Analysis of the Accuracy of Elicited Expectations}

Researchers have many reasons to be interested in the correspondence between subjective expectations and objective realities. Economists invoking RE assumptions should want to know how well such assumptions describe real decision makers. Social planners contemplating provision of information 
to the public on the risks associated with detrimental behaviors (e.g., smoking, drug use, school dropout) should want to know how accurately persons perceive such risks.

Perhaps the most direct way to evaluate the accuracy of elicited expectations is to follow respondents over time and compare the events that they experience with the expectations elicited from them. Research of this type has a long history in calibration studies of cognitive psychologists, discussed in Section 2.2.2. Within economics, the Federal Reserve Consultant Committee on Consumer Survey Statistics (1955) evaluation of the Michigan consumer confidence data argued that "reinterviews provide the only satisfactory way to test the usefulness or relevance of statistics on expectations and intentions." Subsequently, Juster (1966) used data on individual expectations and realizations to evaluate the predictive power of consumer purchase expectations. In the modern literature on probabilistic elicitation, Dominitz (1998) used a one-year follow-up to a preliminary 1993 version of SEE to evaluate the accuracy of respondents' expectations of their weekly earnings. Hurd and McGarry (2002) used mortality realizations to evaluate expectations of survival to ages 75 and 85 elicited from respondents to the HRS in 1992.

Often the longitudinal data necessary to compare expectations with realizations is not available. Then less direct forms of analysis may be informative. When data are collected in repeated cross-sectional surveys, one may compare the expectations elicited from respondents in one wave of the survey with the events realized by respondents in a later wave. Dominitz and Manski (1997b) evaluated the one-year-ahead expectations of SEE respondents interviewed in 1994 in this way, comparing their expectations with the realizations reported by the new sample of respondents interviewed in 1995.A more common way to evaluate accuracy has been to compare mean expectations with historical realizations. Such comparisons assume that successive cohorts of persons have the same distribution of realizations for the event of interest.

In an early study, Hamermesh (1985) used historical mortality data to assess the accuracy of expectations of survival to ages 60 and 80. Hurd and McGarry (1995) used life-table data to evaluate expectations of survival to ages 75 and 85 elicited from HRS respondents of age 51 to 61 in 1992 . The 
NLSY97 elicited the expectations adolescents for survival one-year-ahead and to age 20. In this case, the expectations were wildly pessimistic relative to the life table evidence; see Fischhoff et al. (2000).

A further type of analysis considers situations in which persons are asked about future macro events for which it is reasonable to suppose that they have no private information. In these situations, the RE hypothesis predicts that persons should have the same probabilistic expectations. However, expectations have been found to be highly heterogeneous in practice. Research of this type includes Dominitz and Manski (2003, 2004, 2007, 2011) on expectations of equity returns, Delavande and Manski (2012) on expectations of election outcomes, and Armantier et al. (2013) on inflation expectations. See Sections 4 and 5 for further discussion.

\subsection{Using Choice Expectations to Predict Choice Behavior}

A long term objective of economists engaged in research on expectations is to improve our ability to predict choice behavior. Expectations data may be used to predict behavior in two ways. Persons may be questioned about the choices that they would make in specified scenarios, and the responses used directly to predict their behavior. Or persons may be asked to report their expectations for uncertain states of nature, and these data may be combined with choice data to estimate econometric decision models. I discuss the former approach here and the latter in the next sub-section.

A common practice in market research and psychology, and an occasional one in economics, has been to pose choice scenarios and ask respondents to state deterministically what actions they would choose if they were to face these scenarios. However, Manski (1999) cautioned that stated choices may differ from actual ones if researchers provide respondents with different information than they would have when facing actual choice problems. The norm has been to pose incomplete scenarios, ones in which respondents are given only a subset of the information they would have in actual choice settings. When scenarios are 
incomplete, stated choices are point predictions of uncertain actual choices.

Elicitation of probabilistic choice expectations permits respondents to express uncertainty about their choice behavior in incomplete scenarios. The original Juster (1966) proposal was to elicit consumer subjective probabilities for future purchases and use the responses to predict actual purchases. Hurd and Smith (2002) used probabilistic expectations of bequests provided by HRS respondents to predict the bequests that these persons will make. Probabilistic polling questions have been used to elicit voting probabilities and to predict actual voting behavior; see Delavande and Manski (2010) and Gutsche et al. (2014).

Use of choice expectations to predict actual choice behavior has two noteworthy features, one advantageous and the other disadvantageous. The advantageous feature is that the approach does not require the researcher to know anything about the decision rules that persons use. The disadvantageous feature is that if this approach is to yield accurate predictions, persons should have rational (or at least unbiased) choice expectations and realized choices should be statistically independent (or at least not strongly dependent) across the population; see Manski (1999).

\subsection{Using Expectations and Choice Data to Estimate Econometric Decision Models}

Researchers who employ econometric decision models to predict choice behavior envision using expectations data to relax assumptions about expectations for states of nature. Consider, for example, the situation of labor economists studying schooling behavior. Researchers who observe only the choices that youth make confront a severe identification problem as they seek to infer both preferences and beliefs from data on observed choices. Observation of youths' expectations of the returns to schooling mitigates this problem. Elicitation of entire subjective distributions of life-cycle earnings may be impractical, but a researcher may use whatever expectations data as are available to lessen the dependence of inference on 
assumptions about expectations.

The advantages and disadvantages of this use of expectations data reverse those of the approach discussed in Section 3.3. The advantageous feature is that persons need not have rational expectations; it is enough to assume that elicited expectations faithfully describe persons' perceptions of their environments. The disadvantageous feature is that, given expectations and choice data, econometric modeling still requires assumptions about the distribution of preferences in the population of interest.

Research using probabilistic expectations data in econometric analysis of choice behavior has steadily accumulated over time. Early on, Nyarko and Schotter (2002) used a proper scoring rule to elicit expectations of opponent behavior from experimental subjects playing a two-person game and used the expectations to inform their analysis of decision making by subjects. A large experimental literature performing research of this type has developed subsequently. See the review article of Schotter and Trevino (2014).

A similarly large literature has developed using survey data on expectations in econometric choice analysis. Early on, Hurd, Smith, and Zissimopoulos (2004) investigated how the subjective survival probabilities elicited from HRS respondents affect the times when they choose to retire and to begin collecting Social Security benefits. Lochner (2007) combined NLSY97 data on arrest expectations and crime commission to estimate a random utility model of criminal behavior. Van der Klaauw and Wolpin (2008) used HRS data on survival, retirement, and bequest expectations to help estimate a stochastic dynamic model of savings and retirement behavior. Delavande (2008) surveyed young women regarding their contraceptive choices and elicited expectations for the effectiveness and side effects of alternative methods. She combined expectations and choice data to estimate a random utility model of contraception behavior.

More recently, van der Klaauw (2012) used data on student expectations regarding future occupations to estimate a dynamic model of decisions to have careers in teaching. Zafar (2013) and Wiswall 
and Zafar (2015) surveyed college students regarding their choice of major, elicited expectations for the monetary and non-monetary returns to alternative majors, and combined the expectations and choice date to estimate random utility models of choice of major. Giustinelli (2016) surveyed teenagers completing middle school and their parents regarding choice among alternative types of high school and their expectations for successful performance in each type of school and their outcomes therafter. She used these data to estimate random utility models of choice of high school, recognizing that families may use varying internal household decision processes.

Whereas structural econometric analysis has usually sought to interpret actual choice behavior, researchers have occasionally posed hypothetical choice scenarios, asked respondents to state what actions they would choose in these scenarios, and used the responses as if they are actual choices. As mentioned earlier, stated choices may differ from actual ones if researchers provide respondents with incomplete descriptions of the information that they would have when facing actual choice problems. Given this, Manski (1999) proposed elicitation of choice probabilities rather than deterministic stated choices and showed how the elicited choice probabilities may be used to estimate random utility models. This idea has subsequently been applied by Blass, Lach, and Manski (2010), who analyze consumer willingness to pay

for alternative electricity options with differing prices and reliability of supply. It has also been applied by Delavande and Manski (2015), who specified hypothetical election scenarios, elicited subjective probabilities that respondents would choose to vote in these scenarios, and used the expectations data to estimate a random utility of the decision to vote.

\subsection{Analysis of Expectations Formation}

Econometric models of decision processes often are used to predict behavior following policy interventions or other events that may alter expectations. When this is so, prediction of behavior requires 
an understanding of expectations formation. Macroeconomists have long been sensitive to this requirement, it being a central feature of the Lucas (1976) critique of macroeconomic policy evaluation.

Experimental psychologists and economists have studied how persons update objective probabilities following receipt of sample data in highly structured settings like those presented in textbook statistics exercises. A concern has been to test adherence to and characterize departures from application of Bayes Theorem; see, for example, Tversky and Kahneman (1974) and El-Gamal and Grether (1995). It is, however, difficult to draw lessons from this work for expectations formation in real life, where the information that persons receive rarely maps cleanly into a textbook exercise in probability updating. Bayesian updating, which expresses new information through the likelihood function, presumes that data are generated by a well-defined sampling process. Expectations formation in real life requires persons to assimilate government announcements, media reports, personal observations, and other forms of information that may be generated in obscure ways.

One can learn something about updating in real life by eliciting expectations repeatedly from persons, observing how they change over time, and seeking to interpret the observed changes as responses to accumulation of new information. Dominitz (1998) elicited earning expectations at six-month intervals from a spring 1993 cohort of SEE respondents who were re-interviewed in fall 1993. He examined the association between revisions to expectations and the earnings that respondents realized between interviews. Zafar (2011) elicited expectations of the returns to alternative college majors from a cohort of college sophomores who were re-interviewed a year later. He examined how expectations were updated in light of student course experiences during the sophomore year. Dominitz and Manski (2011) elicited expectations of equity returns at six-month intervals from respondents to the Michigan Survey of Consumers. Their analysis of the data suggests that the population may be composed of a mixture of expectations types, each updating expectations in a stable but different way; see Section 4.2 for further 
discussion of this work. Such research can in principle be performed with other surveys that elicit expectations repeatedly.

One can also learn from information experiments embedded in surveys, which elicit expectations before and after provision of specified information. Delavande (2008b) explored how women revise their expectations about contraceptive effectiveness following receipt of new information. As part of her survey studying contraceptive expectations and choices, Delavande introduced a hypothetical new contraceptive to her respondents, elicited prior expectations for its effectiveness, and then elicited posterior expectations after providing various forms of further information. To analyze the prior and posterior expectations data, she developed the creative idea of an "equivalent random sample," this being the random sample evidence that would lead a Bayesian statistician to make the same revision to expectations as a given respondent was observed to make.

Wiswall and Zafar (2015) designed and executed a survey of college undergraduates that first elicited expectations about their major choices and the returns to alternative majors. They next provided information to respondents on the empirical distribution of earnings of students who had graduated with different majors. They then again elicited expectations following provision of this information. They used the data on prior and posterior expectations to analyze expectations updating by the respondents.

Armantier et al. (2016) first elicited respondent expectations of inflation in the year ahead. They then conducted an information experiment in which they randomly provided some respondents with information about past-year average food price inflation, some with professional economists' median forecast of year-ahead inflation, and others with no information. They subsequently asked all respondents for their expectations of inflation in the year ahead. Their experiment generated an informative panel data set that enabled them to examine how provision of new information induces respondents to update their inflation expectations. 
Similarly, Armona, Fuster, and Zafar (2016) used a survey information experiment to examine how consumers revise expectations for home prices. They first elicited respondents' beliefs about past and future local home price changes. They then presented a random subset of the respondents with factual information about past changes and re-elicited expectations.

\section{Expectations of Equity Returns}

Having summarized the development and concerns of the literature measuring probabilistic expectations in broad populations, I now discuss in more detail work that collects and analyzes data on expectations for macroeconomic events. Two subjects have drawn particular attention, expectations of equity returns and inflation expectations. I address the former here and the latter in Section 5.

\subsection{Competing Perspectives on Heterogeneity of Expectations}

Expectations of equity returns are thought to be central determinants of investment in equities and

other assets. A motivation for microeconomists to collect data on personal expectations of equity returns has been to assess how expectations vary across the population and how heterogeneity in expectations affects individual portfolio decisions.

In the absence of data on expectations, there long has been disagreement about the extent and nature of heterogeneity in beliefs about returns. Much of the theoretical literature in finance has regarded heterogeneity in beliefs as either non-existent or unimportant. However, some researchers have argued that heterogeneity in expectations is critical to the functioning of asset markets.

The original formulation of the capital asset pricing model assumed that all investors hold the same 
expectations for asset returns (Sharpe, 1964; Lintner, 1965). Subsequent discussions asserted that heterogeneity would not affect the basic CAPM conclusions (Lintner, 1969; Sharpe, 1970). Adherents of the efficient markets hypothesis contended that prices reveal all privately held information and concluded that expectations must be homogeneous ex post, even if they are heterogeneous ex ante (Fama, 1970).

In contrast to the above, theoretical research arguing that heterogeneity of expectations exists and matters includes Keynes (1937), Williams (1938), Miller (1977), Mayshar (1983), Harris and Raviv (1993), Kandel and Pearson (1995), and Morris (1995). These researchers reject the core tenet of the efficient market hypothesis that persons begin with common prior beliefs and develop heterogeneous beliefs only because they receive private signals. They stress that persons may hold divergent opinions even when all information is public. They reason that persons may hold disparate beliefs about how asset markets operates and, hence, they may interpret publicly available information differently. Heterogeneity in interpretation of common knowledge has also been a theme of research in behavioral finance; see Daniel, Hirshleifer, and Teoh (2002).

Theoretical argument alone cannot determine whether and how heterogeneity of expectations affects the operation of asset markets. Nor can a traditional form of empirical research that attempts to infer expectations from asset prices. To accomplish this, researchers often pose representative-agent models, which assume away heterogeneity of expectations.

Even when models of investment behavior permit heterogeneity in expectations, asset prices generally do not reveal the distribution of expectations within the population of investors. My simple study interpreting prices in prediction markets is illustrative (Manski, 2006). Prediction markets often ask persons to bet on the occurrence of some event; that is, to take positions on Arrow securities. Various researchers have asserted, without proof, that the observed price on a prediction market is the mean subjective probability of the investors, sometimes called the "market probability" of the event. See, for example, Forsythe et al. (1992) and Wolfers and Zitzewitz (2004). Assuming a population of risk-neutral investors 
who each bet the same amount, I found that the equilibrium price is not the mean subjective probability but rather is a certain quantile of the cross-sectional distribution of expectations. It was subsequently found by Gjerstad (2005) and Wolfers and Zitzewitz (2006) that price equals the mean subjective probability only if investors are risk-averse with utility equal to $\log ($ income). In any case, the price on a prediction market does not reveal the degree to which expectations are heterogeneous.

\subsection{Elicitation of Probabilistic Expectations}

To provide an empirical basis for study of heterogeneous expectations of equity returns, Jeff Dominitz and I designed survey questions measuring in probabilistic terms the beliefs that Americans hold about equity returns in the year ahead. We first posed a series of questions on SEE in 1999-2001 and later placed one of these on the Michigan Survey of Consumers in 2002-2004. Similar questions have appeared since 2002 in the bi-annual administration of the HRS and in some European surveys. Research reporting analysis of these data include Dominitz and Manski (2003, 2004, 2007, 2011), Hurd, van Rooij, and Winter (2011), Hudomiet, Kezdi, and Willis (2011), and Gouret and Hollard (2011). See Ben-David, Graham, and Harvey (2013) for analysis of another panel survey that queried corporate financial executives rather than a general population, eliciting 0.10 and 0.90 quantiles of respondents' subjective distributions of equity returns.

Measurement of probabilistic expectations of equity returns differs sharply from traditional attitudinal surveys that qualitatively classify respondents as "bullish" or "bearish" about the stock market; see, for example, Fisher and Statman (2000). Other surveys have elicited point expectations of equity returns from various samples of respondents. See Vissing-Jorgenson (2004) and Greenwood and Shleifer (2014) for analyses of these data. I will discuss general problems in interpreting point predictions of uncertain events in Section 6.1. 
Cochrane (2011) has called attention to the difficulty of interpreting responses to questions that use imprecise verbal phrases when asking for point predictions of equity returns, writing (p. 1068): “It does not take long in teaching MBAs to realize that the colloquial meanings of 'expect' and 'risk' are entirely different from conditional mean and variance.” Cochrane also conjectured that confounding of beliefs and preferences may occur when surveys elicit point predictions of financial outcomes. He speculated that persons may report so-called risk-neutral expectations rather than pure beliefs, writing (p. 1068):

“If people report the risk-neutral expectation, then many surveys make sense. An 'optimistic' cashflow growth forecast is the same as a "rational" forecast, discounted at a lower rate, and leads to the correct decision, to invest more. And the risk-neutral expectation — the expectation weighted by marginal utilityis the right sufficient statistic for many decisions. Treat painful outcomes as if they were more probable than they are in fact.”

Cochrane’s definition of risk-neutral expectations as "the expectation weighted by marginal utility” posits a specific form of confounding of beliefs and preferences. As far as I am aware, there does not yet exist empirical research seeking to determine whether persons respond to expectations questions on financial risk in this manner. See Section 7.3 for discussion of possible confounding of beliefs and preferences in other contexts.

The basic question in the surveys eliciting probabilistic expectations asks respondents to state the percent chance that a diversified mutual fund will have a positive nominal return in the year ahead. The wording in the Michigan survey was as follows.

"The next question is about investing in the stock market. Please think about the type of mutual fund known as a diversified stock fund. This type of mutual fund holds stock in many different companies engaged in a wide variety of business activities. Suppose that tomorrow someone were to invest one thousand dollars in such a mutual fund. Please think about how much money this investment would be worth one year from now. What do you think is the percent chance that this one-thousand-dollar investment will increase in 
value in the year ahead, so that it is worth more than one thousand dollars one year from now?"

SEE and HRS pose further questions seeking the percent chance that the investment will change in value by more than specified amounts.

The basic descriptive findings are: (a) expectations of a positive nominal return vary substantially across persons and systematically with sex, age, and schooling; (b) the patterns of variation are similar within the Michigan, SEE, and HRS samples; and (c) individual beliefs exhibit considerable stability over time.

Tables 1 and 2 show some of the evidence underlying findings (a) and (b). Table 1, taken from Dominitz and Manski (2011, Table 3), provides summary statistics on the Michigan survey data collected from 2002 to 2004 and the SEE data collected from 1999 to 2001. Table 2, taken form Dominitz and Manski (2007, Table 1), gives statistics on the HRS survey data collected in 2004. Finding (c) emerged from analysis of the longitudinal feature of the Michigan survey, which provides two interviews for most respondents, spaced six months apart.

[INSERT TABLE 1 AND TABLE 2 HERE]

These descriptive findings suggest that individuals use interpersonally variable but intrapersonally stable processes to form their expectations. We proposed (Dominitz and Manski, 2011) that the population may be composed of a mixture of expectations types, each forming expectations in a stable but different way. We presented an exploratory analysis that uses the Michigan and SEE data to learn about the prevalence of different types, focusing on three types suggested by thinking in orthodox and behavioral finance. These are a random-walk ( $R W$ ) type, who believes that returns are independent and identically distributed over time, a persistence $(P)$ type, who believes that recent stock market performance will persist into the near future, and a mean-reversion (MR) type, who believes that recent market performance will be reversed in the near future. Using the time series of the S\&P 500 to measure recent market performance, 
we concluded that processes of expectations formation are very heterogeneous. Applying an ordinal criterion to classify types, we found that the fractions of Michigan respondents who express expectations consistent with the RW, P, and MR types are $0.27,0.41$, and 0.32 respectively.

Whether or not one finds persuasive our classification of persons into (RW, P, MR) types, the observed interpersonal heterogeneity of expectations and intrapersonal stability of expectations provides strong empirical evidence against the hypothesis that persons have rational expectations of equity returns. Ordinary persons may have access to substantial common information about the functioning of equity markets but they rarely have much private information. In the absence of private information, the RE hypothesis predicts that expectations should not vary across persons. Yet respondents to the Michigan, SEE, and HRS surveys expressed large differences in their expectations, which vary systematically across demographic groups and are intrapersonally stable.

\subsection{Expectations and Stock Holdings}

Going beyond measurement of expectations of equity returns, an economist would naturally want to relate expectations to portfolio decisions. Dominitz and Manski (2007) used HRS data to perform an exploratory analysis.

Given some assumptions, a person should hold stocks if his subjective probability of a positive nominal return exceeds his risk-free rate of return. We studied how the fraction of HRS respondents who hold stocks varies with expectations. We found a consistent pattern across groups defined by gender and marital status. In each case, the probability of holding stocks increases substantially as the reported chance of a positive return increases from $0 \%$ to roughly $90 \%$. We also found that the fraction holding stocks declines slightly as the reported chance of a positive return increases further from 90 to $100 \%$. We had no ready explanation for this mildly anomalous behavior at the upper tail. 
Although our analysis was hardly definitive, we think it suggests that research on portfolio choice would benefit by eliciting expectations of equity returns. Indeed, doing so may help to resolve the famous "equity premium puzzle" that many households hold no risky assets. This behavior is puzzling only to the extent that respondents perceive an equity premium to exist.

Haliassos and Bertaut (1995) dismissed the notion that subjective expectations explain the low rate of stockholding, writing (p. 1114): "Heterogeneity of opinions is not promising [as the explanation], since what is required is the perception that a premium exists, not that it is of a particular magnitude." As more promising explanations, they cited inertia and departures from expected-utility maximization. Our empirical evidence suggests that economic theory can generate the observed phenomenon once we reject the practice of making unwarranted assumptions on expectations and bring to bear expectations data instead.

Our findings from the HRS data are consistent with, but do not prove, the following causal claims: (1) investment portfolios become more conservative as households age because households tend to become less optimistic about equity returns, (2) men invest more aggressively than women because they tend to be more optimistic about equity returns, and (3) many households hold no risky assets because they are not as convinced as economists are about the existence of an equity premium.

\section{Inflation Expectations}

Macroeconomists have considered inflation expectations to be a driver of private economic decisions and, hence, to be relevant to formation of monetary policy (e.g., Gali 2008, Sims 2009). A standard way to measure inflation expectations has been to infer them from the observed difference in yields between nominal and real government debt; see, for example, Haubrich et al. (2012). However, the 
difference in yields is easily interpretable only in the context of a representative agent model with strong maintained assumptions about investor risk preferences. Even then it may only provide information on the central tendency of inflation expectations, not about investor uncertainty.

Consumer confidence surveys have long sought to measure inflation expectations within the general population. However, the questions posed have not allowed respondents to express uncertainty. The Michigan Survey of Consumers asks:

"During the next 12 months, do you think that prices in general will go up, or go down, or stay where they are now?"

Those who respond "go up" or "go down" are then asked to give a specific percent.

\subsection{Measurement of Inflation Expectations in the Survey of Consumer Expectations}

With the above background, the Federal Reserve Bank of New York in 2006 initiated a major project developing its new Survey of Consumer Expectations (SCE), which since 2013 has elicited a substantial set of probabilistic expectations from its national sample of respondents. The SCE has a rotating-panel design, measuring respondent expectations monthly for up to twelve consecutive months. Improved measurement of inflation expectations was a major motivation for the SCE. Armantier et al. $(2013,2016)$ discuss the developmental process yielding the SCE and the specifics of the survey design.

Rather than summarize substantive findings obtained to date with the SCE, I call attention here to the differences between the SCE questions eliciting inflation expectations and the questions asked in the Michigan survey. The reason I do so is to emphasize the importance of careful attention to question wording when eliciting expectations.

The team of New York Fed researchers who designed the SCE used an exemplary process to 
evaluate how persons respond to the Michigan questions and then to formulate the SCE questions. They first used small-scale cognitive interviews to learn how respondents interpret and respond to alternative question wordings. They then scaled up their exploration of respondent behavior by posing alternative questions to respondents of the national American Life Panel and analyzing the responses. Only after this and further cognitive interviewing did they finalize the SCE questions.

The SCE elicits both point and probabilistic predictions of inflation, with randomized ordering of these formats. The survey uses a two-stage format to obtain point predictions. Respondents are first asked:

"Over the next 12 months, do you think that there will be inflation or deflation? (Note: deflation is the opposite of inflation)."

Depending on their response, they are next asked for a point estimate:

"What do you expect the rate of [inflation/deflation] to be over the next 12 months? Please give your best guess."

The question format seeking a probabilistic prediction is as follows:

"In your view, what would you say is the percent chance that, over the next 12 months, the rate of inflation will be $12 \%$ or higher percent chance the rate of inflation will be between $8 \%$ and $12 \%$ percent chance the rate of inflation will be between $4 \%$ and $8 \%$ percent chance the rate of inflation will be between $2 \%$ and $4 \%$ percent chance the rate of inflation will be between $0 \%$ and $2 \%$ percent chance the rate of deflation (opposite of inflation) will be between $0 \%$ and $2 \%$ percent chance the rate of deflation (opposite of inflation) will be between $2 \%$ and $4 \%$ percent chance the rate of deflation (opposite of inflation) will be between $4 \%$ and $8 \%$ percent chance the rate of deflation (opposite of inflation) will be between $8 \%$ and 12\% percent chance 
the rate of deflation (opposite of inflation) will be $12 \%$ or higher

percent chance

Total

As respondents enter their answers, they can see what the total sums to. Those who give answers that do not add up to 100 percent receive the notice "Please change the numbers in the table so they add up to 100."

The SCE questions differ from those of the Michigan survey in various ways. I discuss two important differences here.

\subsubsection{Asking about "Inflation" or about "Prices in General"}

Prior to the SCE, surveys seeking consumer expectations of inflation posed questions that avoid use of the word "inflation," the presumption being that ordinary persons may not understand the professional economic use of the term. Instead the Michigan and other surveys have asked about expected changes in "prices in general." The NY Fed researchers were concerned that the term "prices in general" is vague. They were aware of research arguing that respondents may interpret this vague term heterogeneously, each thinking about the prices of products that are important to his or her own consumption pattern. See Armantier et al. (2013).

Given this concern, the NY Fed team performed empirical research aiming to understand how respondents interpret the term "prices in general." As recounted in Armantier et al. (2013), they first conducted cognitive interviews with a small sample to identify potential interpretations of the question. After reading the Michigan question out loud, interviewees were instructed to think out loud while generating their answers. They found that some interviewees recognized the question as asking about inflation, whereas others interpreted it as asking about their personal price experiences.

The team then conducted an internet survey with a larger sample recruited through the ALP, thus obtaining sufficient statistical power to examine the association of question interpretations with responses. Respondents first received the Michigan Survey question about "prices in general" and subsequently rated 
how much they were thinking of different question interpretations taken directly from the cognitive interviews, including "the prices of things you spend money on" and "inflation."

They found that respondents who focused on their personal consumption patterns tended to report higher expectation for the future increase in "prices in general" than did those who thought about overall inflation. They conjectured that certain psychological theories may explain the observed systematic difference in response. These theories predict that consumers pay more attention to price increases than to price decreases, especially if they are large and frequently experienced. When the NY Fed team probed survey respondents about their understanding of changes to "prices in general," they found that a significant fraction believed the intent of the question was to inquire about the prices they recently paid themselves, particularly prices that had increased or decreased markedly, such as those for food or gasoline. They also found that this tendency to think more about prominent price changes in respondents' own price experiences was particularly common among respondents with lower financial literacy.

By contrast, the team found that when they posed questions asking for expectations for the rate of inflation rather than about "prices in general," respondents tended to think less about a few salient price changes specific to their own experience and more about price changes across a broader set of items or about changes in the general cost of living, concepts that align more closely to economists' definition of inflation. They concluded that asking about the rate of inflation directly produces answers more consistent with the concept of inflation expectations of interest to central banks. Based on this experience, the NY Fed team decided that the SCE should inquire directly about "inflation" rather than about "prices in general."

\subsubsection{Probability Elicitation in the SCE}

A second important difference between the Michigan Survey and the SCE is that the former only asks for point predictions while the latter asks for both point and probabilistic predictions. The probabilistic question format used in the SCE is like that used in the Bank of Italy Survey of Household Income and 
Wealth and in the Survey of Professional Forecasters, posing a set of intervals and asking respondents to report their subjective probability that inflation will lie in each interval.

When analyzing the respondent-specific data, the NY Fed team has adopted the parametric density estimate that Engelberg, Manski, and Williams (2009, 2011) proposed and utilized in their studies of predictions made by the Survey of Professional Forecasters, which will be discussed in Section 6. When a respondent assigns a positive probability to three or more bins, this estimate assumes an underlying generalized beta distribution, which has four parameters, two to determine its support and two to determine its shape. When a respondent assigns a positive probability to only one or two bins, the underlying distribution is assumed to have the shape of an isosceles triangle.

Armantier et al. (2013) describe the process used by the NY Fed team to explore the properties of the probabilistic question before they finalized its format. They first fielded the question in a special internet survey and then in an experimental panel survey of consumers that preceded initiation of the SCE. They found that response rates were close to $100 \%$ in both surveys. Only about $1 \%$ of respondents provided assessments that did not add up to $100 \%$.

They found that, when given the opportunity, most respondents chose to express uncertainty in their probabilistic predictions. The proportion of respondents who put positive probability mass in more than one interval was very high: 96\%in the special internet survey and $89 \%$ in the panel surveys. The average number of intervals with positive probability was also high: 4.8 for the special internet survey and 3.8 for the panel surveys. The fraction of respondents who put positive mass in noncontiguous intervals was very low, ranging from $1.3 \%$ in the special survey to $1.6 \%$ in the panel surveys. They found that the probabilistic predictions can be approximated reasonably well by the parametric density estimate, which assumes probabilistic beliefs to be unimodal. They also found that respondent point predictions were highly correlated with the means and medians of the parametric density estimates based on the probabilistic predictions. These and other findings are detailed in Armantier et al. (2013). 


\section{Expectations of Professional Macroeconomic Forecasters}

I now turn from measuring the expectations of broad populations to those of professional macroeconomic forecasters. I begin with the prevailing practice of eliciting point predictions from such forecasters and then discuss probabilistic measurement of their expectations.

\subsection{Problems in Interpreting Point Predictions}

Professional forecasters regularly give point predictions of uncertain future events. For example, panel members in the Survey of Professional Forecasters (SPF) give quarterly point predictions of GDP growth and inflation. These point predictions cannot reveal anything about the uncertainty that forecasters perceive. They at most convey some notion of the central tendency of beliefs.

Suppose that forecasters hold subjective probability distributions for future events. Point predictions should somehow be related to the probabilistic expectations that forecasters hold, but how? Forecasters may report the means of their probability distributions for uncertain events or they may report medians or modes. However, forecasters typically are not asked to report means, medians, or modes. They are simply asked to "predict" or "forecast" the outcome. In the absence of explicit guidance, forecasters may report different distributional features as their point predictions. Research calling attention to and analyzing the potential heterogeneity of response practices include Elliott, Komunjer, and Timmermann (2005, 2008), Engelberg, Manski, and Williams (2009), and Clements (2009).

Heterogeneous reporting practices can be consequential for the interpretation of point predictions. Forecasters who hold identical probabilistic beliefs may provide different point predictions, and forecasters 
with dissimilar beliefs may provide identical point predictions. If so, comparison of point predictions across forecasters is problematic. Variation in predictions need not imply disagreement among forecasters, and homogeneity in predictions need not imply agreement.

Macroeconomic researchers have sometimes interpreted cross-forecaster dispersion in point predictions to indicate disagreement in their beliefs. See, for example, Diether, Malloy, and Scherbina (2002), Mankiw, Reis, and Wolfers (2004), Patton and Timmermann (2010), and Coibion and Gorodnichenko (2012). If forecasters vary in the way they transform probability distributions into point predictions, this interpretation confounds variation in forecaster beliefs with variation in the manner that forecasters make point predictions.

A distinct, and more severe, interpretative problem is the longstanding use of cross-sectional dispersion in macroeconomic point predictions to measure forecaster uncertainty about future outcomes. See, for example, Cukierman and Wachtel (1979), Levi and Makin (1979, 1980), Makin (1982), Brenner and Landskroner (1983), Hahm and Steigerwald (1999), Hayford (2000), Giordani and Söderlind (2003), Johnson (2004), Barron, Stanford, and Yu (2009), Güntay and Hackbarth (2010), and Bachmann, Elstner, and Sims (2013). This research practice is illogical even if all forecasters make their point predictions in the same way. Even in the best of circumstances, point predictions provide no information about the uncertainty that forecasters perceive. This point was made forcefully thirty years ago by Zarnowitz and Lambros (1987). Nevertheless, researchers have continued to use the dispersion in point predictions to measure forecaster uncertainty.

Yet another issue is the common practice of aggregating point predictions into a combined forecast. Empirical researchers have long reported that the cross-sectional mean or median of a set of point predictions is more accurate than the individual predictions used to form the mean or median. In a review of this practice in macroeconomic forecasting, Clemen (1989) states (p. 559): 
"The results have been virtually unanimous: combining multiple forecasts leads to increased forecast accuracy. This has been the result whether the forecasts are judgmental or statistical, econometric or extrapolation. Furthermore, in many cases one can make dramatic performance improvements by simply averaging the forecasts."

This phenomenon is sometimes colloquially called the "wisdom of crowds." It has only occasionally been recognized that these regularities have algebraic foundations, which do not imply that a combined forecast has any absolute degree of accuracy. The regularity concerning mean predictions holds whenever a convex loss function (or concave welfare function) is used to measure prediction accuracy, by Jensen's inequality. The one concerning median predictions holds whenever a unimodal loss or welfare function is used to measure accuracy. See Manski (2011a, 2016) for discussion of the literature and for analysis.

\subsection{Empirical Research on Probabilistic Expectations}

The above suggests that it would be more informative to elicit probabilistic predictions from professional forecasters. Indeed, the SPF asks its panel members to provide both point and probabilistic forecasts of inflation and GDP growth (www.phil.frb.org/econ/spf/). The probabilistic forecasts are subjective probabilities that the outcome will lie in each of ten intervals. An important feature of the SPF is that the survey has a longitudinal component, with many forecasters providing multiple predictions over the course of several years. ${ }^{3}$

\footnotetext{
${ }^{3}$ Another panel survey has collected partial probabilistic expectations from professionals. A Duke University survey of senior finance executives at American firms has asked respondents to predict the return to the S\&P 500 in the year ahead. The Duke survey used this question format:

"Over the next year, I expect the annual S\&P 500 return will be:

- There is a 1-in-10 chance the actual return will be less than $\%$

- I expect the return to be: _ \%

- There is a 1-in-10 chance the actual return will be greater than __ \%"

See Ben-David, Graham, and Harvey (2013) for analysis of these data. The Duke survey also collects point predictions of outcomes in respondents' firms, but not probabilistic predictions. See Gennaioli, Ma, and Schleifer (2016) for analyses of these data.
} 
To shed empirical light on the reporting practices of professional forecasters, Engelberg, Manski, and Williams (2009) used data from the SPF to compare point predictions of GDP growth and inflation with the subjective probability distributions held by forecasters. We found that the deviations between point predictions and the central tendencies of forecasters' subjective distributions tend to be asymmetric, with SPF forecasters tending to report point predictions that give a more favorable view of the economy than do their subjective means/medians/modes. We concluded that organizations commissioning forecasts should not ask for point predictions. Instead, they should elicit probabilistic expectations and derive measures of central tendency and uncertainty.

In subsequent research, Engelberg, Manski, and Williams (2011) showed the value of probabilistic expectations data when one seeks to characterize the temporal variation of macroeconomic forecasts. It has been common to aggregate the point predictions reported by SPF panel members at each administration of the survey into a "consensus prediction" and analyze the time series of this aggregate. Summary reports of SPF findings traditionally take this form.

We observed that interpretation of the temporal variation in aggregated predictions can be problematic for multiple reasons: (a) Aggregate predictions reveal nothing about the uncertainty that forecasters perceive. (b) They reveal nothing about possible disagreement across the panel of forecasters. (c) Aggregate predictions ignore the fact that the composition of panels of forecasters often change substantially over time. Examining the data on expectations of inflation and GDP growth obtained by the SPF in the period 1992-2006, we concluded that the interpretative problem is always serious in principle and often in practice.

To replace analysis of aggregated predictions, we recommended study of the time series of the probabilistic forecasts made by individual forecasters. Considering each forecaster separately, one may compute parameters that measure the central tendency and spread of elicited subjective probability distributions; we suggested use of the subjective median and interquartile range. This done, a plot showing 
the subjective (median, IQR) of each forecaster clearly portrays the heterogeneity of forecasts at a point in time. To describe the evolution of expectations across the quarterly administrations of the survey, we recommended enhancing the plot with arrows to indicate how each forecaster changes his beliefs from one quarter to the next.

Figures from our article, reproduced here, illustrate. The top panel of Figure 1 displays the subjective medians and IQRs for 2001 GDP growth elicited from forecasters who participated in the SPF in 3Q2001 and 4Q2001. Thus, the figure shows GDP growth expectations before and after the terrorist attacks of September 11, 2001. Each forecaster is depicted by an arrow whose tail is his 3Q2001 prediction and whose tip is his 4Q2001 prediction. The figure shows that nearly all forecasters revised their subjective medians downward between 3Q2001 and 4Q2001. However, forecasters varied in the direction of revisions to their subjective IQRs, some becoming more certain about output growth and others less certain.

The bottom panel of the figure displays the subjective medians and IQRs for 2006 inflation elicited from forecasters who participated in the SPF in both 3Q2005 and 4Q2005. Thus, the figure shows inflation expectations before and after Ben Bernanke's nomination to be Chair of the Board of Governors of the Federal Reserve System on October 24, 2005. The figure shows that most forecasters revised their subjective medians upwards but they varied considerably in the magnitude of the revision. Revisions to subjective IQRs were heterogeneous in both direction and magnitude.

[INSERT FIGURE 1 HERE]

\subsection{Communicating Uncertainty and Disagreement in the Macroeconomic Forecasts of Central Banks}

I find it intriguing to compare the forecasting practice of the Bank of England with that of the U.S. Federal Reserve System. The Bank of England uses fan charts to visually portray the probabilistic forecasts of inflation and GDP growth made by the Bank's Monetary Policy Committee (MPC) in its quarterly 
Inflation Report. The Board of Governors of the Federal Reserve periodically releases a Summary of Economic Projections summarizing forecasts made by the participants in the deliberations of the Federal Open Market Committee (FOMC). Each participant is asked to make point predictions of GDP growth, inflation, and the unemployment rate in each of several future years. The Summary of Economic Projections describes the distribution of the point predictions across the FOMC participants.

The MPC and the FOMC both present forecasts as distributions. One may think that these distributions are conceptually similar, but they are apples and oranges. A fan chart gives a consensus MPC expression of forecast uncertainty, suppressing possible disagreements among the MPC members. A distribution presented in the Summary of Economic Projections describes the diversity of point forecasts made by participants in FOMC deliberations, suppressing whatever uncertainty each person may feel.

To illustrate, suppose that the MPC and the FOMC both forecast that inflation in a future year will lie in the range one to three percent. The MPC forecast means that the consensus judgment of MPC members is that there is zero probability that the inflation rate will be less than one percent or more than three percent. The FOMC forecast means that no FOMC member made a point forecast of the inflation rate that was less than one percent or more than three percent.

The SPF and similar European panels have demonstrated the feasibility and usefulness of eliciting probabilistic predictions from panels of macroeconomic forecasters. The members of the MPC and FOMC should similarly be capable of providing informative probabilistic predictions. The MPC and the FOMC could obtain such forecasts and communicate the findings regularly to the public.

\section{$\underline{\text { 7. Probabilistic Thinking and Communication }}$}

There is by now extensive empirical evidence that survey respondents are willing and able to report 
expectations in probabilistic form. Given this, empirical economic research analyzing data on probabilistic expectations has increasingly sought to achieve substantive objectives. Researchers usually presume that elicited expectations accurately express the beliefs that persons hold regarding future events. Maintaining this assumption, they aim to learn what expectations persons hold and they use expectations data to help understand and predict choice behavior. Thus, collection and analysis of probabilistic expectations data has become part of normal economic science.

There has, nevertheless, been awareness that the willingness and ability of respondents to report probabilistic expectations does not imply that persons regularly think probabilistically and use subjective probability distributions to make decisions. It has long been known that survey respondents are willing and able to respond to questions seeking point predictions of uncertain events or verbal assessments of likelihood. Yet persons need not use point predictions or verbal assessments of likelihood to make decisions. What the evidence does show is that, however they think and act, people are willing and able to report their beliefs in multiple forms--as point predictions, verbal assessments of likelihood, or probabilistic expectations. See Wallsten et al. $(1986,1993)$ for analysis of this phenomenon.

This section discusses research that aims to interpret elicited probabilistic expectations, seeking to shed light on how persons respond to the questions posed and how to improve question design, so as to enhance the usefulness of expectations data. Section 7.1 considers the common practice of rounding by survey respondents. Section 7.2 addresses the possibility that persons may perceive ambiguity (aka Knightian uncertainty) when contemplating uncertain future events. Section 7.3 considers the possibility that persons may confound beliefs and preferences.

\subsection{Rounding}

Rounding is the familiar practice of reporting one value whenever a real number lies in an interval. 
Consider meteorological reports of wind direction. Reports issued to the public commonly delineate 8 directions (e.g., north, northeast, east). Those to aircraft pilots delineate 36 directions (e. g., 10, 20, 30 degrees).

Whereas the extent of rounding is common knowledge in standardized communications such as weather reports, recipients of rounded data may be unsure of the extent of rounding in other settings. Uncertainty about the extent of rounding is common when researchers analyze survey responses to numerical questions. Questionnaires do not request that respondents round to a specified degree. There are no firm conventions for rounding responses. Hence, researchers cannot be sure how much rounding there may be in survey data.

Rounding of responses to questions eliciting probabilistic expectations is common and sometimes is substantial enough to warrant attention. Dominitz and Manski (1997b) observed that respondents to SEE tended to report values at one-percent intervals at the extremes (i.e., 0, 1, 2 and 98, 99, 100) and at five or ten-percent intervals elsewhere (i.e., 5,10, . , 90, 95), with responses more bunched at 50 percent than at adjacent round values (40, 45, 55, 60). These findings have been corroborated repeatedly in other surveys.

It is evident that respondents round their responses to subjective probability questions, but to what extent? When someone states "3 percent," one might reasonably infer that the person is rounding to the nearest one percent. However, when someone states "30 percent," one might be uncertain whether the person is rounding to the nearest one, five, or ten percent. Even more uncertain is how to interpret responses of 0 , 50, and 100 percent. These may sometimes be sharp expressions of beliefs, but some respondents may engage in gross rounding, using 0 to express any relatively small chance of an event, 50 to represent any intermediate chance, and 100 for any relatively large chance.

Moreover, survey data do not reveal why sample members give rounded expectations responses. Some persons may hold precise subjective probabilities for future events but round their responses to simplify communication. Others may perceive the future as partially ambiguous and, hence, not feel able 
to place precise probabilities on events. Thus, a response of "30 percent" could mean that a respondent believes that the percent chance of the event is in the range $[20,40]$ but feels incapable of providing finer resolution.

Considering extreme cases of ambiguity, Fischhoff and Bruine de Bruin (1999) and Bruine de Bruin et al. (2000) suggested that when respondents feel unable to assign any subjective probability to an event, they may report the value 50 to signal epistemic uncertainty, as in the loose statement 'It's a fifty-fifty chance.' This idea is formally interpretable as the grossest possible form of rounding, where 50 means that the percent chance lies in the interval [0, 100]. Lillard and Willis (2001) offered an alternative interpretation of rounding for communication, in which respondents first form full subjective distributions for the probability of an event and then report whichever of the three values $(0,50,100)$ is closest to the mode of this subjective distribution.

Although survey data do not directly reveal the extent or reasons for rounding in observed responses, analysis of patterns of responses across questions and respondents can be informative. Manski and Molinari (2010) performed such analysis, focusing on the expectations module in the 2006 administration of the HRS. We found that, for each question posed, the great preponderance of the responses are multiples of five, most responses are multiples of ten, and a moderate minority are multiples of 50 . Examining the module as a whole, we found that sample members vary considerably in their response tendencies. A small fraction used only the values $(0,50,100)$ throughout the module. Most respondents made fuller use of the $0-100$ percent chance scale. About 0.26 at least once used a multiple of ten that is not one of the values $(0,50,100)$, about 0.51 at least once used a multiple of five that is not a multiple of ten, and about 0.12 at least once used a value that is not a multiple of five. We proposed use of a person's response pattern across questions to infer the person's rounding practice, the result being interpretation of reported numerical values as interval data.

Further analysis of rounding and related reporting behavior in the HRS has been performed by 
Kleinjans and Van Soest (2014). They develop a panel data model of reporting behavior and estimate it using responses to the HRS from 1994 through 2010. See also Ruud, Schunk, and Winter (2014), who use experimental evidence to conclude that increasing uncertainty makes respondents more likely to round.

\subsection{Ambiguity}

Among economists and decision theorists, perhaps the most compelling alternatives to the hypothesis of probabilistic expectations have been put forward in research on decisions under ambiguity. Studies of ambiguity maintain that beliefs have some but not all the structure of a probability distribution. The beginning of modern study of decision making under ambiguity is usually associated with Ellsberg (1961). Early discussions appear in Keynes (1921) and Knight (1921).

A particularly common idea has been that a person may hold a set of subjective distributions for an unknown event, not a single distribution. This idea is a primitive of research on robust Bayes analysis (e.g., Berger, 1985), which supposes that persons hold multiple subjective distributions prior to observing data, and it is a conclusion of some work in axiomatic decision theory (e. g., Gilboa and Schmeidler, 1989). It is also a conclusion of my research on partial identification of probability distributions, which shows that combining available data with credible assumptions may enable a decision maker to partially but not fully identify an objective probability distribution (e.g., Manski, 2000, 2011b). Walley (1991) and Camerer and Weber (1992) review parts of the literature.

Suppose that beliefs take the form of sets of subjective distributions. Then the single distributions that we now elicit from survey respondents are probabilistic summaries of ambiguity, much as point predictions are deterministic summaries of uncertainty. To enable persons to express ambiguity, survey researchers could elicit ranges of probabilities rather than precise probabilities for events of interest. This is straightforward in the case of binary events, for which one can pose questions such as 
What do think is the percent chance that event A will occur? Please respond with a particular value or a range of values, as you see fit.

This format enables respondents to express whatever uncertainty or ambiguity they may feel. A respondent can express complete ignorance by reporting “0 to 100 percent," bounded ambiguity by reporting “30 to 70 percent,” uncertainty by reporting “60 percent,” or certainty by reporting “100 percent.”

Wallsten, Forsyth, and Budescu (1983) and Manski and Molinari (2010) have reported exploratory research on responses to questions of this type. The objective of the latter work was to probe beneath the evidence of rounding and try to distinguish between rounding for communication and rounding as an expression of ambiguity. I explain here.

We posed a sequence of expectations questions to 552 respondents to the American Life Panel. The first asked an often-studied HRS question about survival expectations, seeking the percent-chance that the respondent gives to living to age 75 . We then followed up with these questions:

Q1. When you said [X percent] just now, did you mean this as an exact number or were you rounding or approximating?

If a person answered "rounding or approximating," we then asked

Q2. What number or range of numbers did you have in mind when you said [X percent]?

When the response to Q1 is "an exact number," one can reasonably conclude that rounding was minimal. When the response is "rounding or approximating," one can use the response to Q2 to interpret the data. If a person responds with an exact (non-rounded) number, we think it reasonable to conclude that he was 
rounding for communication. If he responds with a range, he was rounding to express ambiguity.

All of the respondents answered question Q1. Of the 552 respondents, 264 reported that their response to the survival question was an exact answer and the remaining 288 reported that they had rounded or approximated. Within the group of 288 persons who were asked Q2, all but two responded. Among them, 70 persons reported that they had an exact number in mind and 248 that they had a range in mind. These numbers sum to more than 288 because 31 persons reported that they had both an exact number and a range in mind. Among the 248 who reported a range in response to Q2, the average width of the reported interval was 17.6 percent.

The results of this exploratory work were encouraging. Respondents to the ALP showed no resistance to being probed about the interpretation of their reported survival probabilities. If questions Q1 and Q2 had been placed on the 2006 HRS, it would have been possible to use the responses to infer rounding rather than the less direct approach we used to assign intervals based on response patterns to standard probabilistic questions.

\subsection{Confounding Beliefs and Preferences}

Research on decision making under ambiguity weakens the traditional economic assumption that persons place precise subjective probability distributions on future events, but it maintains the traditional assumption that persons separate their beliefs and preferences. The distinction between beliefs and preferences is expressed in decision theory by supposing that a person choosing an action from a choice set C specifies a state space $\mathrm{S}$ that lists all possible states of nature and a state-dependent utility function U(c, s) that values each action $c \in C$ in each state $s \in S$. The utility function expresses preferences. The state space expresses a basic form of belief, differentiating between those states that can possibly occur and those that cannot. Placing a precise or a partial subjective distribution on the state space may strengthen the 
specification of beliefs.

Although separation of beliefs and preferences remains a standard assumption of applied economic analysis, economists have increasingly been willing to theorize about choice behavior with modes of decision making that confound beliefs and preferences. See, for example, Ackerlof and Dickens (1982), Caplin and Leahy (2001), Brunnermeier and Parker (2005), Gollier and Muermann (2010), Cochrane (2011), and Bénabou and Tirole (2016).

\subsubsection{Evidence in Research Measuring Probabilistic Expectations}

Measuring expectations in a survey is a well-defined task if persons separate their beliefs and preferences. It is less clear how to interpret expectations data if persons confound beliefs and preferences.

There has long been concern that the verbal questions used in attitudinal research may be susceptible to confounding. For example, if one asks a person to state whether it is "likely" or "unlikely" that an event will occur, the concern has been that the person's interpretation of these words may depend on the nature of the event. One of the most basic arguments for elicitation of probabilistic rather than verbal expectations has been that probability provides a well-defined absolute numerical scale for responses. Hence, there is reason to think that responses may be comparable across persons and events.

Accepting the traditional decision theoretic separation of beliefs and preferences, modern research eliciting probabilistic expectations has generally assumed that responses measure beliefs alone, not beliefs confounded with preferences. The empirical evidence has broadly seemed consistent with this assumption. As discussed earlier, survey responses usually have high face validity (Section 3.1). They often are reasonably accurate when compared with objective frequencies, even if not so much as to warrant being called rational expectations (Section 3.2). Moreover, there has been considerable success (in the sense of obtaining sensible findings) using elicited probabilistic expectations to replace expectations assumptions when estimating econometric models of expected utility maximization (Section 3.4). 
The above generalizations notwithstanding, there have been occasional settings in which elicited probabilistic expectations may confound beliefs and preferences. In Section 3.1, I noted that teenagers interviewed in the NLSY97 often gave highly inaccurate responses when asked to predict their chance of dying in the next year or the next several years. Their responses tended to wildly overstate the chance of dying, relative to the empirical evidence in life tables; see Fischhoff et al. (2000). One might speculate that their responses conflated the risk of dying with the severity of the event. On the other hand, analysis of HRS data on the expectations of older adults to survive to age 75 has shown these expectations to be reasonably accurate when compared to life tables; see Hurd and McGarry (1995, 2002). It may be that older adults can think separately about the risk of death and its finality, but teenagers are not able to do so. Measurement of risk of crime victimization may be another setting in which persons confound beliefs with preferences. The attitudinal research literature has long been concerned with confounding of responses to verbal questions in this domain. Numerous surveys ask respondents about their fear of crime (see Warr, 1994). Ferraro and LaGrange (1987) argue that such questions confound two concepts—-the perceived risk of crime and the emotional response to crime- that need not be strongly associated. In fact, they argue that the empirical evidence suggests these two phenomena are not strongly positively related and, for some criminal activities, may be negatively related.

Dominitz and Manski (1997b) analyzed probabilistic expectations of burglary elicited in the SEE in 1994. We found a pervasive tendency of respondents to overpredict the risk of burglary in the year ahead. Among men, the mean subjective probability of burglary was 0.16 , whereas the realized rate at which SEE respondents had been victims of burglary in the previous year was 0.05 . Among women, the mean subjective probability was 0.17 and the realized fraction burglarized was 0.03 . Our findings on beliefs about risk victimization corroborate the conventional wisdom that Americans perceive crime to be far more prevalent than it actually is (see Bursik and Grasmick 1993, chap. 4). We could not, however, offer a compelling rationale for the phenomenon. In personal communications, some researchers suggested to us 
that persons tend to be pessimistic about the likelihood of traumatic events. Yet we found no tendency towards pessimism regarding other adverse events—job loss and absence of health insurance-that arguably are as traumatic as burglary.

It is not clear whether confounding of beliefs and preferences explains teenager overstatement of the risk of mortality and adult overstatement of the risk of crime victimization. If confounding does explain these empirical phenomena, one must ask why researchers have not found analogous overstatements when eliciting probabilistic expectations of other personal risks.

\section{Looking Ahead: Studying Expectations Formation to Inform Macro Policy Analysis}

Economists were long hostile to measurement of expectations. In my earlier review of the modern literature (Manski, 2004), I wrote that caution is prudent but hostility is not warranted. By the early 2000s, we had already learned enough that I felt able to recommend that economists should abandon their antipathy to measurement of expectations. I felt comfortable asserting that persons usually respond informatively to questions eliciting probabilistic expectations for personally significant events. I observed that the unattractive alternative to measurement of expectations is to make unsubstantiated assumptions.

Writing now, I can easily reinforce what I wrote then. We have since the early 2000s amassed a very substantial new body of longitudinal data on the probabilistic expectations of the American population through additions to the HRS and through initiation of the ALP and SCE. We have, moreover, learned much through collection of data in special surveys undertaken in many countries to provide data for particular research projects. These new data and the analyses they have enabled strongly corroborate my earlier belief that researchers should measure expectations routinely and use the data to improve our understanding of important features of economic behavior under uncertainty. 
While the modern literature has developed mainly with a concern for applications to microeconomics, I see enormous potential for use of probabilistic expectations data in macroeconomics as well. I expect that macroeconomists should find informative much of the data and analysis discussed in this article, particularly the knowledge accumulated of expectations of equity returns (Section 4), inflation expectations (Section 5), and the expectations of macroeconomic forecasters (Section 6). Moreover, macroeconomists who plan to design and analyze new expectations questions should be able to draw useful lessons about the need for careful attention to question wording (Sections 2.2 and 5.1) and how persons respond to probabilistic expectations questions (Section 7).

I concluded my earlier review article with a call for study of expectations formation, writing (Manski, 2004, p. 1371):

“Looking beyond measurement, I see a critical need for basic research on expectations formation. Understanding how persons revise their expectations with receipt of new information often is a prerequisite for credible use of econometric decision models to predict behavior.”

Several studies have been performed subsequently (see Sections 3.5 and 4.2), but there remains a critical need for sustained research on expectations formation. Indeed, understanding expectations formation is even more essential to macroeconomics than it is to microeconomics.

Consider, for example, research on the operation of equity markets. A microeconomist may want to learn the distribution of risk and time preferences in a population of potential investors. To achieve this objective, he may obtain a random sample of the population, measure their expectations of returns to equities and other assets, observe their portfolio choices, and use the data to estimate a structural econometric model that assumes each member of the population makes a choice that maximizes expected utility. A macroeconomist may want to use the estimated structural model to predict the dynamics of equity prices that would occur after announcement of an unanticipated change in fiscal or monetary policy. To 
achieve this objective, one needs to do more than measure the current expectations of equity returns in the population of investors. One needs also to forecast how investors update their expectations after announcement of the policy change and as they observe the subsequent market dynamics.

Similarly, consider research on labor markets. A microeconomist may want to learn the distribution of labor-leisure preferences in a population of potential workers. To achieve this objective, he may obtain a random sample of the population, measure their expectations of life-cycle after-tax earnings under alternative labor-supply choices, observe their actual choices, and use the data to estimate a structural model that assumes each person chooses labor supply to maximize expected utility. A macroeconomist may want to use the estimated structural model to predict the dynamics of market wages and aggregate employment after announcement of an unanticipated policy change, such as a change in the income tax schedule. To achieve this objective, one needs to do more than measure current expectations of life-cycle earnings in the population. One needs to forecast how persons would update their expectations after they learn of the new policy and as they observe the subsequent dynamics of the labor market.

\subsection{The Dynamics of Macroeconomic Perspectives on Expectations Formation}

Over forty years ago Lucas (1976) powerfully called attention to the importance of understanding expectations formation when one attempts to predict the outcomes of new macroeconomic policies. Lucas pointed out that optimizing individuals and firms may update their expectations following receipt of new information and revise decisions accordingly. He observed that the econometric models used in the 1970s to predict macro policy outcomes lacked microfoundations. He specifically criticized the failure of these models to distinguish anticipated policy changes, whose enactment should not affect expectations, from unanticipated changes, whose enactment may affect expectations.

Given his critique of the then-prevalent econometric practice, Lucas might have recommended that 
economists initiate empirical research on expectations formation in order to improve macroeconomic policy analysis. However, he made no such recommendation. Instead, he advocated that macroeconomists should assume that economic agents have rational expectations.

Early in his article, considering Friedman's permanent income model of consumption, Lucas wrote (p. 27) that the model "lacks content" if expectations are viewed as subjective and becomes meaningful only if rational expectations are assumed. Later, considering forecasting in generality, he asserted that assuming rational expectations is a prerequisite for predicting agent behavior, writing (p. 41):

"It is perhaps necessary to emphasize that this point of view towards conditional forecasting, due originally to Knight and, in modern form, to Muth, does not attribute to agents unnatural powers of instantly divining the true structure of policies affecting them. More modestly, it asserts that agents' responses become predictable to outside observers only when there can be some confidence that agents and observers share a common view of the nature of the shocks which must be forecast by both.”

Lucas did not explain why he believed that the permanent income model "lacks content” without an RE assumption. Nor did he prove that prediction of agent behavior is possible "only" when rational expectations is assumed. He made these assertions as if they are self-evident. I see no logical reason why RE should be a necessary assumption in macroeconomic analysis. As far as I am aware, neither Lucas nor other macroeconomists have ever provided a logical argument for the necessity of assuming that agents have rational expectations.

Even if the assumption of rational expectations is not necessary for macro policy analysis, it is analytically appealing and has been used because it enables researchers to close their models in a succinct and tidy manner. Woodford (2013) put it this way (p. 304):

"The dominant approach for the past several decades of course has made use of the hypothesis of modelconsistent or rational expectations (RE): the assumption that people have probability beliefs that coincide 
with the probabilities predicted by one's model. The RE benchmark is a natural one to consider, and its use has allowed a tremendous increase in the sophistication of the analysis of dynamics in the theoretical literature in macroeconomics.”

Yet Woodford and other macroeconomists have increasingly questioned the credibility of the assumption and have entertained alternatives to it. Continuing the passage quoted above, Woodford (2013) wrote (p. 304):

"Nonetheless, the assumption is a strong one, and one may wonder if it should be relaxed, especially when considering relatively short-run responses to disturbances, or the consequences of newly adopted policies that have not been followed in the past-both of which are precisely the types of situations that macroeconomic analysis frequently seeks to address.”

Given this motivation, Woodford proceeded to contrast the assumptions and implications of several different ways of relaxing the assumption of rational expectations. Not surprisingly, he showed that the manner in which a model of expectations formation deviates from RE is consequential for prediction of macro outcomes following policy changes.

The large recent literature cited by Woodford makes plain that macroeconomists have increasingly been willing to pose and study models of expectations formation that do not assume RE. See also Sims (2003), Burnside, Eichenbaum, and Rebelo (2016), Eusepi and Preston (2016), and the literatures cited there. However, the new literature being almost entirely theoretical, models of expectations formation have proliferated without evidence on their realism. Woodford (2013) called attention to this in his conclusion, writing (p. 343):

"It may be asked how macroeconomic analysis can be possible with such a wide range of candidate assumptions. One answer would be that empirical studies should be undertaken to determine which of these possible specifications of subjective expectations best describe observed behavior. A few studies of that kind already exist, but the empirical literature remains at a fairly early stage.” 
Woodford's call for empirical research on expectations formation is welcome. However, I doubt that the theoretical literature developed thus far will provide a satisfactory foundation for empirical research. A potentially large problem is that theorists have typically assumed everyone forms expectations in the same way. For example, Eusepi and Preston (2016) write (p. 11): "agents are assumed to have identical beliefs, though they do not understand this to be true as they have no knowledge of the tastes and beliefs of other agents." Near the end of their review article, they briefly suggest moving away from this assumption as a direction for future research, writing (p. 47): “The second dimension where the literature could and should expand is to abandon the assumption of homogeneous expectations.”

Assuming homogeneous expectations can greatly simplify theoretical analysis, but this paper has called attention to considerable empirical evidence of substantial heterogeneity in the expectations of households and professional forecasters. Given this, I think it essential to question the robustness of forecasts made with models that assume homogeneous expectations. Where such forecasts are not sufficiently robust, I anticipate that macroeconomists will find it necessary to give up the simplicity of homogeneous expectations and strive to develop tractable models of economies in which agents have flexibly heterogeneous expectations.

When macroeconomists undertake empirical research, I do not expect that it will be possible to learn very much about expectations formation if only data on observed behavior are studied. The problem, as I emphasized in Section 2.1, is that revealed-preference analysis of choice under uncertainty requires the researcher to infer from observed behavior both preferences and beliefs, not preferences alone. To reiterate, empirical analysis confronts a severe identification problem: an observed choice made by an agent maximizing expected utility may be consistent with many plausible utility functions and subjective probability distributions. 


\subsection{The Potential Contribution of Expectations Measurement}

As described in this paper, measurement of expectations can enable more fruitful study of expectations formation. To make progress, I urge measurement and analysis of the revisions to expectations that agents make following occurrence of unanticipated shocks. Sections 3.5 and 4.2 described some studies that have performed two types of such research. Both types first measure expectations at a specified point in time and then measure revised expectations after provision of new information. They differ in how the new information is provided and when revised expectations are measured.

Some studies re-interview persons at later points in time and examine the revisions to expectations that they make following the occurrence of actual new events. Other studies provide information within the survey and then elicit posterior expectations immediately. Studies of the former type are appealing because they examine real-time revisions to expectations in response to actual informational shocks, but they have the disadvantage that the researcher does not know what new information respondents obtained. Studies of the latter type have opposing advantages and disadvantages: the researcher controls provision of new information, but the setting is artificial.

To give a small sense of what may be learned with data of the first type, consider the expectations

of professional macroeconomic forecasters depicted graphically in the top panel of Figure 1 . The panel displays the subjective medians and IQRs for 2001 GDP growth elicited from thirteen forecasters who participated in the SPF in both 3Q2001 and 4Q2001. Thus, the figure shows GDP growth expectations before and after the terrorist attacks of September 11, 2001. Each forecaster is depicted by an arrow whose tail is his 3Q2001 prediction and whose tip is his 4Q2001 prediction.

Examination of the 3Q2001 predictions shows moderate heterogeneity in GDP growth expectations prior to the attacks. Across the SPF panel, the subjective median forecast varied from 0.011 to 0.018 and the subjective IQR varied from 0.005 to 0.013 . The terrorist attacks and the policy response that followed 
provide a classic case of an unanticipated shock. The figure shows that nearly all forecasters revised their median forecast downward between 3Q2001 and 4Q2001, but the magnitude of the revision varied greatly across forecasters. The median forecast of four forecasters remained essentially unchanged. Eight forecasters reduced their median growth forecast moderately (by about 0.025 to 0.01 ). One reduced his median forecast substantially, lowering it from 0.015 to -0.005 . Forecasters also varied in the direction of revisions to their subjective IQRs, with some becoming more certain about output growth and others becoming less certain.

The evident heterogeneity across forecasters in GDP growth predictions is hard to reconcile with the assumption of rational expectations. It is similarly hard to reconcile with the RE assumption the heterogeneity of forecasts in the bottom panel of Figure 1, which shows 3Q2005 inflation predictions and the revisions that forecasters made to these predictions in 4Q2005, after Bernanke's nomination to be Chair of the Fed Board. An RE assumption is plainly inconsistent with the observed heterogeneity in the expectations of the SPF panel if forecasters have common knowledge of the state of the economy. To rescue the RE assumption would require that SPF members possess differential private information that makes their prior predictions and revisions to expectations vary as shown in the figure.

I expect that study of revisions to expectations such as in Figure 1 will enable macroeconomists to make progress learning about expectations formation. However, I do not think that measurement of revisions to expectations per se will suffice to guide macroeconomic policy analysis. To develop credible models of expectations formation, it will be important to study how persons obtain and interpret new information over time.

To reiterate a point made in Section 3.5, economists have generally modeled revision to expectations as a process of Bayesian updating, which expresses new information through the likelihood function. This presumes that data are generated by a well-defined sampling process. However, revision of 
macroeconomic expectations in real life requires persons to assimilate government announcements, media reports, personal observations, and other forms of information that may be generated in obscure ways.

Introspecting about how I revise my own macroeconomic expectations after receipt of new information, I often find it difficult to conjecture an explicit sampling process. Hence, I am unable to consciously update in the Bayesian manner. Yet I somehow do revise my expectations and find that I can express a posterior subjective probability distribution. If my experience is typical, it will be a challenge to develop realistic models of expectations formation by individuals and firms. 


\section{References}

Akerlof, G. and W. Dickens (1982), “The Economic Consequences of Cognitive Dissonance,” American Economic Review, 72, 307-319.

Armantier, O., W. Bruine de Bruin, S. Potter, G. Topa, W. Van der Klaauw, and B. Zafar (2013), "Measuring Inflation Expectations," Annual Review of Economics, 5, 273-301.

Armantier, O., W. Bruine de Bruin, G. Topa, W. Van der Klaauw, and B. Zafar (2015), "Inflation Expectations and Behavior: Do Survey Respondents Act on Their Beliefs?” International Economic Review, 56, 505-536.

Armantier, O., S. Nelson, G. Topa, W. Van der Klaauw, and B. Zafar (2016), "The Price is Right: Updating of Inflation Expectations in a Randomized Price Information Experiment," Review of Economics and Statistics, 98, 503-523.

Armantier, O., W. G. Topa, W. Van der Klaauw, and B. Zafar (2016), "An Overview of the Survey of Consumer Expectations," Staff Report No. 800, Federal Reserve Bank of New York.

Armona, L. A. Fuster, and B. Zafar (2016), "Home Price Expectations and Behavior: Evidence from a Randomized Information Experiment,” Staff Report No. 798, Federal Reserve Bank of New York.

Bachmann, R. and S. Elstner (2015): "Firm optimism and pessimism.” European Economic Review, 79, 297-325.

Bachmann, R., S. Elstner, and E. Sims (2013), "Uncertainty and Economic Activity: Evidence from Business Survey Data,” American Economic Journal: Macroeconomics, 5, 217- 249.

Barron, O., M. Stanford, and Y. Yu (2009), "Further evidence on the Relation between Analysts' Forecast Dispersion and Stock Returns," Contemporary Accounting Research, 26, 329-357.

Bénabou, R. and J. Tirole (2016), "Mindful Economics: The Production, Consumption, and Value of Beliefs,” Journal of Economic Perspectives, 30, 141-164.

Ben-David, I., J. Graham, and C. Harvey (2013), “Managerial Miscalibration,” Quarterly Journal of Economics, 128, 1547-1584.

Berger, J. (1985), Statistical Decision Theory and Bayesian Analysis, New York: Springer-Verlag.

Beyth-Marom, R. (1982), "How Probable is Probable? A Numerical Translation of Verbal Probability Expressions," Journal of Forecasting, 1, 257-269.

Brenner, M. and Y. Landskroner (1983), "Inflation Uncertainties and Returns on Bonds," Economica, 50, 463-468.

Blass, A., S. Lach, and C. Manski (2010), "Using Elicited Choice Probabilities to Estimate Random Utility Models: Preferences for Electricity Reliability," International Economic Review, 51, 421-440. 
Bruine de Bruin, W. and B. Fischhoff (2017): "Eliciting Probabilistic Expectations: Collaborations Between Psychologists and Economists," Proceedings of the National Academy of Sciences, forthcoming.

Bruine de Bruin, W., B. Fischhoff, B. Halpern-Felsher, and S. Millstein (2000), "Expressing Epistemic Uncertainty: It’s a Fifty-Fifty Chance," Organizational Behavior and Human Decision Processes, 81, 115131.

Bruine de Bruin, W., C. Manski, G. Topa, and W. van der Klaauw (2011), "Measuring Consumer Uncertainty about Future Inflation,” Journal of Applied Econometrics, 26, 454-78.

Brunnermeier, M. and J. Parker (2005), “Optimal Expectations,” American Economic Review, 95, 10921118.

Burnside, C., M. Eichenbaum, and S. Rebelo (2016), "Understanding Booms and Busts in Housing Markets,” Journal of Political Economy, 124, 1088-1147.

Bursik, R. and H. Grasmick (1993), Neighborhoods and Crime, New York: MacMillan.

Caballero, R. (1990), “Consumption Puzzles and Precautionary Savings," Journal of Monetary Economics, 25, 113-136.

Camerer, C. and M. Weber (1992), "Recent Developments in Modeling Preferences: Uncertainty and Ambiguity,” Journal of Risk and Uncertainty, 5, 325-370.

Caplin, A.and J. Leahy (2001), "Psychological Expected Utility Theory and Anticipatory Feelings," Quarterly Journal of Economics, 116, 55-80.

Carroll, C. (1992), "The Buffer-Stock Theory of Saving: Some Macroeconomic Evidence," Brookings Papers on Economic Activity, 2, 61-156.

Clemen, R. (1989), "Combining Forecasts: A Review and Annotated Bibliography," International Journal of Forecasting, 5, 559-583.

Clements, M. (2009), "'Internal Consistency of Survey Respondents' Forecasts: Evidence Based on the Survey of Professional Forecasters," in The Methodology and Practice of Econometrics, J. Castle and N. Shephard (editors), Oxford: Oxford University Press.

Cochrane, J. (2011), "Presidential Address: Discount Rates," Journal of Finance, 66, 1047-1108.

Coibion, O. and Y. Gorodnichenko (2012), "What Can Survey Forecasts Tell Us about Informational Rigidities?” Journal of Political Economy, 120, 116-159.

Cukierman, A. and P. Wachtel (1979), "Differential Inflationary Expectations and the Variability of the Rate of Inflation: Theory and Evidence," American Economic Review, 69, 595-609.

Curtin, R. (1982), "Indicators of Consumer Behavior: The University of Michigan Surveys of Consumers," Public Opinion Quarterly, 46, 340-352. 
Daniel, K., D. Hirshleifer, and S. Teoh (2002), "Investor Psychology in Capital Markets: Evidence and Policy Implications," Journal of Monetary Economics, 49, 139-209.

Delavande, A. (2008a), "Pill, Patch, or Shot? Subjective Expectations and Birth Control Choice," International Economic Review, 49, 999-1042.

Delavande, A. (2008b), "Measuring Revisions to Subjective Expectations," Journal of Risk and Uncertainty, 36, 43-82.

Delavande, A. (2014), "Probabilistic Expectations in Developing Countries," Annual Review of Economics, 6, 1-20.

Delavande, A. and C. Manski (2010), "Probabilistic Polling and Voting in the 2008 Presidential Election: Evidence from the American Life Panel," Public Opinion Quarterly, 74, 433-459.

Delavande, A. and C. Manski (2012), "Candidate Preferences and Expectations of Election Outcomes," Proceedings of the National Academy of Sciences, 109, 3711-3715.

Delavande, A. and C. Manski (2015), "Using Elicited Choice Probabilities in Hypothetical Elections to Study Decisions to Vote," Electoral Studies, 38, 28-37.

Diether, K., C. Malloy, and A. Scherbina (2002), "Differences of Opinion and the Cross Section of Stock Returns," Journal of Finance, 57, 2113-2141.

Dominitz, J. (1998), "Earnings Expectations, Revisions, and Realizations," Review of Economics and Statistics, 80, 374-388.

Dominitz, J. and C. Manski (1997a), "Using Expectations Data to Study Subjective Income Expectations," Journal of the American Statistical Association, 92, 855-867.

Dominitz, J. and C. Manski (1997b), "Perceptions of Economic Insecurity: Evidence from the Survey of Economic Expectations," Public Opinion Quarterly, 61, 261-287.

Dominitz, J. And C. Manski (2003), "How Should We Measure Consumer Confidence (Sentiment)? Evidence from the Michigan Survey of Consumers," National Bureau of Economic Research Working Paper 9926.

Dominitz, J. and C. Manski (2004), "How Should We Measure Consumer Confidence?" Journal of Economic Perspectives, 18, 51-66.

Dominitz, J. and C. Manski (2007), "Expected Equity Returns and Portfolio Choice: Evidence from the Health and Retirement Study," Journal of the European Economic Association, 5, 369-379.

Dominitz, J. and C. Manski (2011), "Measuring and Interpreting Expectations of Equity Returns," Journal of Applied Econometrics, 26, 352-370.

Dominitz, J, C. Manski, and B. Fischhoff (2001), "Who are Youth At-Risk?: Expectations Evidence in the 
NLSY-97," in R. Michael (editor), Social Awakenings: Adolescents 'Behavior as Adulthood Approaches, New York: Russell Sage Foundation, 230-257.

El-Gamal, M. and D. Grether (1995), "Are People Bayesian? Uncovering Behavioral Strategies," Journal of the American Statistical Association," 90, 1137-1145.

Elliott, G., I. Komunjer, and A. Timmermann (2005), "Estimation and Testing of Forecast Rationality under Flexible Loss," Review of Economic Studies, 72, 1107-1125.

Elliott, G., I. Komunjer, and A. Timmermann (2008), "Biases in Macroeconomic Forecasts: Irrationality or Asymmetric Loss?" Journal of European Economic Association, 6, 122-157.

Ellsberg, D. (1961), "Risk, Ambiguity, and the Savage Axioms," Quarterly Journal of Economics, 75, 643669.

Engelberg, J. C. Manski, and J. Williams (2009), "Comparing the Point Predictions and Subjective Probability Distributions of Professional Forecasters," Journal of Business and Economic Statistics, 27, 3041.

Engelberg, J., C. Manski, and J. Williams (2011), "Assessing the Temporal Variation of Macroeconomic Forecasts by a Panel of Changing Composition," Journal of Applied Econometrics, 26, 1059-1078.

Erev, I. and B. Cohen (1990), "Verbal versus Numerical Probabilities: Efficiency, Biases, and the Preference Paradox," Organizational Behavior and Human Decision Processes, 45, 1-18.

Eusepi, S. and B. Preston (2016), “The Science of Monetary Policy: An Imperfect Knowledge Perspective,” Journal of Economic Literature, forthcoming.

Fama, E. (1970), "Efficient Capital Markets: A Review of Theory and Empirical Work," Journal of Finance, 25, 383-417.

Federal Reserve Bank of Atlanta (2017), Decision Maker Survey, https://www.frbatlanta.org/research/surveys/decision-maker/?panel=1, accessed February 23, 2017.

Federal Reserve Consultant Committee on Consumer Survey Statistics (1955), Smithies Committee report in Reports of the Federal Reserve Consultant Committees on Economic Statistics. Hearings of the Subcommittee on Economic Statistics of the Joint Committee on the Economic Report, 84th U.S. Congress.

Ferraro, K. and R. LaGrange (1987), “'The Measurement of Fear of Crime,’ Sociological Inquiry, 57, 70101.

Ferrell, W. and P. McGoey (1980), "A Model of Calibration for Subjective Probabilities," Organizational Behavior and Human Performance, 26, 32-53.

Fischhoff, B . and W. Bruine de Bruin (1999), "Fifty-Fifty = 50\%?" Journal of Behavioral Decision Making, 12, 149-163.

Fischhoff, B., A. Parker, W. Bruine de Bruin, J. Downs, C. Palmgren, R. Dawes, and C. Manski (2000), 
“Teen Expectations for Significant Life Events," Public Opinion Quarterly, 64, 189-205.

Fisher, K. and M. Statman (2000), “Investor Sentiment and Stock Returns,” Financial Analysts Journal, 56, 16-23.

Forsythe, R., F. Nelson, G. Neumann, and J. Wright (1992), "Anatomy of an Experimental Political Stock Market," American Economic Review, 82, 1142-1161.

Friedman, M. and L. Savage (1948), "The Utility Analysis of Choices Involving Risk," Journal of Political Economy, 56, 279-304.

Gali J. (2008), Monetary Policy, Inflation and the Business Cycle: An Introduction to the New Keynesian Framework, Princeton: Princeton University Press.

Gennaioli, N., Y, Ma, and A. Schleifer (2016), “Expectations and Investment,” NBER Macroeconomics Annual 2015, Chicago: University of Chicago Press.

Gjerstad, S. (2005), "Risk Aversion, Beliefs, and Prediction Market Equilibrium," Economic Science Laboratory, University of Arizona.

Gigerenzer, G. (1991), "How to Make Cognitive Illusions Disappear: Beyond Heuristics and Biases," European Review of Social Psychology, 2, 83-115.

Gilboa, I. and D. Schmeidler (1989), "Maxmin Expected Utility with Non-Unique Prior," Journal of Mathematical Economics, 18, 141-153.

Giordani, P. and P. Söderlind (2003), "Inflation Forecast Uncertainty," European Economic Review, 47, 1037-1059.

Giustinelli, P. (2016), "Group Decision Making With Uncertain Outcomes: Unpacking Child-Parent Choice of the High School Track," International Economic Review, 57, 573-602.

Gollier C. and A. Muermann (2010), "Optimal Choice and Beliefs with Ex Ante Savoring and Ex Post Disappointment,” Management Science, 56, 1272-1284.

Gosselin, M. and M. Kahn (2015), “A Survey of Consumer Expectations for Canada,” Bank of Canada Review, Autumn, 14-23.

Gouret F. and G. Hollard (2011), "When Kahneman meets Manski: Using Dual Systems of Reasoning to Interpret Subjective Expectations of Equity Returns," Journal of Applied Econometrics, 26, 371-392.

Greenwood, R. and A. Schleifer (2014), "Expectations of Returns and Expected Returns," Review of Financial Studies, 27, 714-746.

Guiso, L., T. Jappelli, and D. Terlizzese (1992), “Earnings Uncertainty and Precautionary Saving,” Journal of Monetary Economics, 30, 307-337. 
Guiso, L., T. Jappelli, and L. Pistaferri (2002), "An Empirical Analysis of Earnings and Employment Risk,” Journal of Business and Economic Statistics, 20, 241-253.

Guiso, L. and G. Parigi (1999), "Investment and Demand Uncertainty,” Quarterly Journal of Economics, $114,185-227$.

Güntay, L. and D. Hackbarth (2010), "Corporate Bond Credit Spreads and Forecast Dispersion," Journal of Banking \& Finance, 34, 2328-2345.

Gutsche, T., A. Kapteyn, E. Meijer, and B. Weerman (2014), "The RAND Continuous 2012 Presidential Election Poll," Public Opinion Quarterly, 78, S233-S254.

Hahm, J. and D. Steigerwald (1999), "Consumption Adjustment under Time-Varying Income Uncertainty," Review of Economics and Statistics, 81, 32-40.

Haliassos, Michael, and Carol C. Bertaut (1995), "Why Do So Few Hold Stocks?" Economic Journal, 105, 1110-1129.

Hall, R., and F. Mishkin (1982), "The Sensitivity of Consumption to Transitory Income: Estimates from Panel Data on Households," Econometrica, 50, 461-477.

Hamermesh, D. (1985), "Expectations, Life Expectancy, and Economic Behavior," Quarterly Journal of Economics, 100, 389-408.

Harris, M. and A. Raviv (1993), "Differences of Opinion Make a Horse Race," Review of Financial Studies, 6, 473-506.

Haubrich, J, G. Pennachi, and P. Ritchken (2012), "Inflation Expectations, Real Rates, and Risk Premia: Evidence from Inflation Swaps,” Review of Financial Studies, 25, 1588-1629.

Hayford, M. (2000), "Inflation Uncertainty, Unemployment Uncertainty, and Economic Activity," Journal of Macroeconomics, 22, 315-329.

Hoffrage, U., S. Lindsey, R. Hertwig, and G. Gigerenzer (2000), "Communicating Statistical Information,” Science, 290, 2261-2262.

Hudomiet, P., G. Kezdi, and R. Willis (2011), "Stock Market Crash and Expectations of American Households," Journal of Applied Econometrics, 26, 393-415.

Hurd, M. (2009), "Subjective Probabilities in Household Surveys," Annual Review of Economics, 1, 543564.

Hurd, M. and K. McGarry (1995), "Evaluation of the Subjective Probabilities of Survival in the Health and Retirement Study," Journal of Human Resources, 30, S268-S292.

Hurd, M. and K. McGarry (2002), "The Predictive Validity of Subjective Probabilities of Survival," The Economic Journal, 112, 966-985. 
Hurd, M. and J. Smith (2002), "Expected Bequests and Their Distribution," NBER Working Paper 9142.

Hurd, M., J. Smith, and J. Zissimopoulos (2004), "The Effects of Subjective Survival on Retirement and Social Security Claiming," Journal of Applied Econometrics, 19, 761-775.

Hurd, M., M. van Rooij, and J. Winter (2011), "Stock Market Expectations of Dutch Households," Journal of Applied Econometrics, 26, 416-436.

Johnson, T. (2004), "Forecast dispersion and the cross section of expected returns," Journal of Finance, 59, 1957-1978.

Juster,T. (1964), Anticipations and Purchases, Princeton: Princeton University Press.

Juster, T. (1966), "Consumer Buying Intentions and Purchase Probability: An Experiment in Survey Design," Journal of the American Statistical Association, 61, 658-696.

Juster, T. and R. Suzman (1995), "An Overview of the Health and Retirement Study," Journal of Human Resources, 30, S7-S56.

Kandel, E. and N. Pearson (1995), "Differential Interpretation of Public Signals and Trade in Speculative Markets," Journal of Political Economy, 103, 831-872.

Katona, G. (1957), "Federal Reserve Board Committee Reports on Consumer Expectations and Savings Statistics," Review of Economics and Statistics, 39, 40-46.

Keynes J. (1921), A Treatise on Probability. London: MacMillan.

Keynes, J. (1937), "The General Theory of Employment," Quarterly Journal of Economics, 51, 209-223.

Kleinjans, K. and A. Van Soest (2014), "Rounding, Focal Point Answers and Nonresponse to Subjective Probability Questions,” Journal of Applied Econometrics, 29, 567-585.

Knight F. (1921), Risk, Uncertainty, and Profit. Boston: Houghton-Mifflin.

Koriat, A., S. Lichtenstein, and B. Fischhoff (1980), "Reasons for Confidence," Journal of Experimental Psychology: Human Learning and Memory, 6, 107-118.

Levi, M. and J. Makin (1979), "Fisher, Phillips, Friedman and the Measured Impact of Inflation on Interest," Journal of Finance, 34, 35-52.

Levi, M. and J. Makin (1980), "Inflation Uncertainty and the Phillips Curve: Some Empirical Evidence," American Economic Review, 70, 1022-1027.

Lichtenstein, S., B. Fischoff, and L. Phillips (1982), "Calibration of Probabilities: The State of the Art to 1980," in Kahneman D, Slovic P, Tversky A (eds.) Judgment Under Uncertainty: Heuristics and Biases, New York: Cambridge University Press.

Lichtenstein, S. and R. Newman (1967), "Empirical Scaling of Common Verbal Phrases Associated With 
Numerical Probabilities," Psychonomic Science, 9, 563-564.

Lillard, L. and R. Willis (2001), "Cognition and Wealth: The Importance of Probabilistic Thinking," Michigan Retirement Research Working Paper MRRC WP UM00-04, University of Michigan.

Linden, F. (1982), "The Consumer as Forecaster," Public Opinion Quarterly, 46, 353-360.

Lintner, J. (1965), "The Valuation of Risk Assets and the Selection of Risky Investments in Stock Portfolios and Capital Budgets," Review of Economics and Statistics, 47, 13-37.

Lintner, J. (1969), "The Aggregation of Investors' Diverse Judgements and Preferences in Purely Competitive Markets," Journal of Financial and Quantitative Analysis, 4, 347-400.

Lochner, L. (2007), "Individual Perceptions of the Criminal Justice System," American Economic Review, 97, 444-460.

Lucas, R. (1976), “Econometric Policy Evaluation: A Critique,” Carnegie-Rochester Conference Series on Public Policy, 1, 19-46.

Makin, J. (1982), "Anticipated Money, Inflation Uncertainty, and Real Economic Activity," Review of Economics and Statistics, 64, 126-134.

Mankiw, G. R. Reis, and J. Wolfers (2003), "Disagreement about Inflation Expectations," NBER Macroeconomics Annual 2002, Chicago: University of Chicago Press, 209-248.

Manski, C. (1993), "Adolescent Econometricians: How Do Youth Infer the Returns to Schooling?” in C. Clotfelter and M. Rothschild (editors), Studies of Supply and Demand in Higher Education, Chicago: University of Chicago Press, 43-57.

Manski, C. (1999), "Analysis of Choice Expectations in Incomplete Scenarios," Journal of Risk and Uncertainty, 19, 49-66.

Manski, C. (2000), "Identification Problems and Decisions Under Ambiguity: Empirical Analysis of Treatment Response and Normative Analysis of Treatment Choice,” Journal of Econometrics, 95, 415-442.

Manski C. (2004), "Measuring Expectations," Econometrica, 72, 1329-1376.

Manski, C. (2006), "Interpreting the Predictions of Prediction Markets," Economic Letters, 91, 425-429.

Manski, C. (2011a), "Interpreting and Combining Heterogeneous Survey Forecasts," in M. Clements and D. Hendry (editors), Oxford Handbook on Economic Forecasting, Oxford: Oxford University Press, 457472.

Manski, C. (2011b), “Choosing Treatment Policies under Ambiguity,” Annual Review of Economics, 3, 2549.

Manski, C. (2016), "Interpreting Point Predictions: Some Logical Issues," Foundations and Trends in Accounting, 10, 238-261. 
Manski, C. and F. Molinari (2010), "Rounding Probabilistic Expectations in Surveys," Journal of Business and Economic Statistics, 28, 219-231.

Manski, C. and J. Straub (2000), "Worker Perceptions of Job Insecurity in the Mid-1990s: Evidence from the Survey of Economic Expectations," Journal of Human Resources 35, 447-479.

Mayshar, J. (1983), "On Divergence of Opinion and Imperfections in Capital Markets," American Economic Review, 73, 114-128.

McClelland, A. and F. Bolger (1994), "The Calibration of Subjective Probabilities: Theories and Models 1980-94," in G. Wright and P. Ayton (editors), Subjective Probability, New York: Wiley.

Miller, E. (1977), "Risk, Uncertainty, and Divergence of Opinion," Journal of Finance, 32, 1151-1168.

Morris, S. (1995), "The Common Prior Assumption in Economic Theory," Economics and Philosophy, 11, 227-253.

Morrison, D. (1979), "Purchase Intentions and Purchase Behavior," Journal of Marketing, 43, 65-74.

National Bureau of Economic Research (1960), The Quality and Economic Significance of Anticipations Data, Princeton: Princeton University Press.

Nyarko, Y. and A. Schotter (2002), "An Experimental Study of Belief Learning Using Elicited Beliefs," Econometrica, 70, 971-1005.

Patton, A. and A. Timmermann (2010), "Why Do Forecasters Disagree? Lessons from the Term Structure of Cross-Sectional Dispersion,” Journal of Monetary Economics, 57, 83-120.

Pesaran, H. (1987), The Limits to Rational Expectations, Oxford: Blackwell.

Piazzesi, M. and M. Schneider (2009), "Momentum Traders in the Housing Market: Survey Evidence and a Search Model,” American Economic Review, 99, 406-11.

Ruud, P., D. Schunk, and J. Winter (2014): “Uncertainty Causes Rounding: an Experimental Study,” Experimental Economics, 17, 391-413.

Samuelson, P. (1938), “A Note on the Pure Theory of Consumer Behavior,” Economica, 5, 61-71.

Samuelson, P. (1948), “Consumption Theory in Terms of Revealed Preferences,” Economica, 15, 243-253.

Savage, L. (1971), "Elicitation of Personal Probabilities and Expectations," Journal of the American Statistical Association, 66, 783-801.

Schotter, A. and I. Trevino (2014), "Belief Elicitation in the Laboratory," Annual Review of Economics, 6, 103-128.

Sharpe W. (1964), "Capital Asset Prices: A Theory of Market Equilibrium under Conditions of Risk," 
Journal of Finance, 19, 452-442.

Sharpe W. (1970), Portfolio Theory and Capital Markets, New York: McGraw-Hill.

Shuford, E., A. Albert, and H. Massengill (1966), "Admissible Probability Measurement Procedures," Psychometrika, 31, 125-145.

Sims, C.A. (2003), "Implications of Rational Inattention," Journal of Monetary Economics, 50, 665-690.

Sims C. (2009), "Inflation Expectations, Uncertainty and Monetary Policy," Working Paper 275, Bank for International Settlements, Basel, Switzerland.

Skinner, J. (1988), "Risky Income, Life Cycle Consumption and Precautionary Savings," Journal of Monetary Economics, 22, 237-255.

Souleles, N. (2004), "Expectations, Heterogeneous Forecast Errors, and Consumption: Micro Evidence from the Michigan Consumer Sentiment Surveys," Journal of Money, Credit, and Banking, 36, 39-72.

Tversky, A. and D. Kahneman (1974), "Judgement Under Uncertainty: Heuristics and Biases," Science, 185, 1124-1131.

U.S. Census Bureau (1988), Current Population Reports, Series P-20, No. 427, Fertility of American Women: June, 1987, Washington, D.C.: U.S. Government Printing Office.

U. S. Census Bureau (2016), 2015 Management and Organizational Practices Survey, https://www.census.gov/mcd/mops/, accessed February 23, 2017.

van der Klaauw, W. (2012), "On the Use of Expectations Data in Estimating Structural Dynamic Models," Journal of Labor Economics, 30, 521-554.

van der Klaauw, W. and K. Wolpin (2008), "Social Security and the Retirement and Savings Behavior of Low-Income Households," Journal of Econometrics, 145, 21-42.

Vissing-Jorgenson, A. (2004), "Perspectives on Behavioral Finance: Does 'Irrationality' Disappear with Wealth? Evidence from Expectations and Actions,” NBER Macroeconomics Annual 2003, Cambridge: MIT Press.

Walley, P. (1991), Statistical Reasoning with Imprecise Probabilities, London: Chapman \& Hall.

Wallsten, T., B. Forsythe, and D. Budescu (1983), "Stability and Coherence of Health Experts' Upper and Lower Subjective Probabilities about Dose-response Functions," Organizational Behavior and Human Performance, 31, 227-302.

Wallsten, T., D. Budescu, A. Rapoport, R. Zwick, and B. Forsyth (1986), "Measuring the Vague Meanings of Probability Terms," Journal of Experimental Psychology: General, 115, 348-365.

Wallsten T., D. Budescu, R. Zwick, and S. Kemp (1993), "Preferences and Reasons for Communicating Probabilistic Information in Verbal or Numerical Terms," Bulletin of the Psychonomic Society, 31, 135- 
138.

Warr, M. (1994), "Public Perceptions and Reactions to Violent Offending and Victimization," in Understanding and Preventing Violence, ed. A. Reiss and J. Roth. Vol. 4. Washington, DC: National Academy Press.

Williams J. (1938), The Theory of Investment Value, Cambridge, MA: Harvard University Press.

Wiswall, M. and B. Zafar (2015), "Determinants of College Major Choice: Identification using an Information Experiment," Review of Economic Studies, 82, 791-824.

Wolfers, J. and E. Zitzewitz (2004), "Prediction Markets," Journal of Economic Perspectives, 18, 107-126.

Wolfers, J. and E. Zitzewitz (2006), "Interpreting Prediction Market Prices as Probabilities," NBER Working Paper 12200.

Woodford, M. (2013), "Macroeconomic Analysis without the Rational Expectations Hypothesis,” Annual Review of Economics, 5, 303-346.

Zafar, B. (2011), "How do College Students Form Expectations,” Journal of Labor Economics, 29, 301348.

Zafar, B. (2013), “College Major Choice and the Gender Gap,” Journal of Human Resources, 48, 545-595.

Zarnowitz, V. and L. Lambros (1987), "Consensus and Uncertainty in Economic Prediction," Journal of Political Economy, 95, 591-621.

Zeldes, S. (1989), "Optimal Consumption with Stochastic Income: Deviations from Certainty Equivalence," Quarterly Journal of Economics, 104, 275-298.

Zimmer, A. (1983), "Verbal vs. Numerical Processing of Subjective Probabilities," in R. Scholz (editor) Decision Making Under Uncertainty, North-Holland, Amsterdam.

Zimmer, A. (1984), "A Model for the Interpretation of Verbal Predictions," International Journal of ManMachine Studies, 20, 121-134. 
Table 1: Expectations of Positive Nominal Equity Return (by attribute) Source: Dominitz and Manski (2011, Table 3).

\begin{tabular}{|c|c|c|c|c|c|c|c|c|}
\hline \multirow{3}{*}{ attribute } & \multicolumn{4}{|c|}{ Michigan Data } & \multicolumn{4}{|c|}{ SEE Data } \\
\hline & \multirow{2}{*}{\multicolumn{2}{|c|}{$\begin{array}{l}\text { sample size } \\
\text { total non- } \\
\end{array}$}} & \multirow[t]{2}{*}{ mean } & \multirow[t]{2}{*}{ std dev } & \multicolumn{2}{|c|}{ sample size } & \multirow[t]{2}{*}{ mean } & \multirow[t]{2}{*}{ std dev } \\
\hline & & & & & total & $\begin{array}{l}\text { non- } \\
\text { response }\end{array}$ & & \\
\hline all persons & 7411 & $(609)$ & 46.4 & 29.4 & 1212 & (439) & 68.0 & 27.5 \\
\hline male & 3363 & $(175)$ & 50.2 & 30.0 & 625 & $(149)$ & 68.7 & 26.9 \\
\hline female & 4048 & $(434)$ & 43.2 & 28.5 & 587 & $(290)$ & 67.3 & 28.1 \\
\hline non-Hisp. white & 5833 & (426) & 47.3 & 29.3 & 993 & (348) & 68.8 & 26.8 \\
\hline non-Hisp. black & 610 & (76) & 41.6 & 28.9 & 85 & (33) & 64.7 & 30.8 \\
\hline Hispanic & 547 & (64) & 44.9 & 29.9 & - & - & - & - \\
\hline American Indian & 70 & (4) & 36.4 & 28.3 & 10 & (9) & 58.5 & 36.1 \\
\hline Asian & 160 & (11) & 45.4 & 31.7 & 29 & (6) & 60.8 & 29.7 \\
\hline age $18-34$ & 1804 & $(82)$ & 51.0 & 26.7 & 361 & (91) & 68.9 & 25.3 \\
\hline age $35-49$ & 2520 & $(132)$ & 48.4 & 28.4 & 411 & (98) & 70.0 & 26.9 \\
\hline age 50-64 & 1863 & $(125)$ & 45.9 & 30.9 & 265 & $(114)$ & 67.8 & 27.6 \\
\hline age $65^{+}$ & 1178 & (261) & 36.1 & 30.2 & 152 & (122) & 62.3 & 31.8 \\
\hline schooling 0-12 & 2494 & (375) & 40.1 & 28.6 & 151 & $(140)$ & 59.1 & 31.6 \\
\hline schooling 13-15 & 2116 & (126) & 46.9 & 29.0 & 382 & (139) & 68.8 & 27.8 \\
\hline schooling $16+$ & 2745 & $(92)$ & 51.6 & 29.2 & 607 & (129) & 70.5 & 25.0 \\
\hline
\end{tabular}


Table 2. Expectations of Positive Nominal Return (PNR), By Attribute

2004 Health and Retirement

Study

Source: Dominitz and Manski (2007, Table 1)

\begin{tabular}{|c|c|c|c|c|c|c|c|c|c|c|c|c|c|c|}
\hline \multirow[b]{3}{*}{ Attribute } & \multicolumn{7}{|c|}{ Male } & \multicolumn{7}{|c|}{ Female } \\
\hline & \multirow{2}{*}{$\begin{array}{c}\text { Number of } \\
\text { Respondents } \\
\text { to PNR }\end{array}$} & \multirow[b]{2}{*}{ Mean } & \multirow{2}{*}{$\begin{array}{c}\text { Standard } \\
\text { Deviation }\end{array}$} & \multicolumn{3}{|c|}{ Quantile } & \multirow{2}{*}{$\begin{array}{c}\text { Rate of } \\
\text { Response } \\
\text { to PNR } \\
\end{array}$} & \multirow{2}{*}{$\begin{array}{c}\text { Number of } \\
\text { Respondents } \\
\text { to PNR } \\
\end{array}$} & \multirow[b]{2}{*}{ Mean } & \multirow{2}{*}{$\begin{array}{l}\text { Standard } \\
\text { Deviation }\end{array}$} & \multicolumn{3}{|c|}{ Quantile } & \multirow{2}{*}{$\begin{array}{c}\text { Rate of } \\
\text { Response } \\
\text { to PNR }\end{array}$} \\
\hline & & & & 0.25 & 0.50 & 0.75 & & & & & 0.25 & 0.50 & 0.75 & \\
\hline All Respondents & 5683 & 53.7 & 27.0 & 40 & 50 & 75 & 0.92 & 7247 & 46.0 & 25.7 & 25 & 50 & 60 & 0.83 \\
\hline \multicolumn{15}{|l|}{$\frac{\text { Married or Living }}{\underline{\text { with a Partner }}}$} \\
\hline No & 1080 & 49.6 & 28.0 & 30 & 50 & 75 & 0.87 & 2691 & 43.7 & 26.4 & 20 & 50 & 60 & 0.79 \\
\hline Yes & 4603 & 54.6 & 26.7 & 40 & 50 & 75 & 0.93 & 4556 & 47.3 & 25.3 & 30 & 50 & 60 & 0.86 \\
\hline \multicolumn{15}{|l|}{ Age } \\
\hline $50-59$ & 1745 & 55.2 & 25.8 & 40 & 50 & 75 & 0.93 & 2401 & 48.1 & 25.1 & 30 & 50 & 65 & 0.88 \\
\hline $60-69$ & 2241 & 54.2 & 27.0 & 40 & 50 & 75 & 0.92 & 2889 & 46.8 & 25.7 & 25 & 50 & 60 & 0.84 \\
\hline $70-80$ & 1697 & 51.4 & 28.2 & 30 & 50 & 75 & 0.90 & 1957 & 42.1 & 26.2 & 20 & 50 & 50 & 0.78 \\
\hline \multicolumn{15}{|l|}{$\frac{\text { Holds Stocks or }}{\text { Mutual Funds No }}$} \\
\hline Yes & 3590 & 50.0 & 27.9 & 30 & 50 & 70 & 0.89 & 4759 & 43.1 & 25.9 & 20 & 50 & 60 & 0.79 \\
\hline & 2093 & 60.0 & 24.3 & 50 & 60 & 80 & 0.97 & 2488 & 51.6 & 24.4 & 40 & 50 & 70 & 0.94 \\
\hline
\end{tabular}


Figure 1: Change in Expectations around Events

Source: Englelberg, Manski, and Williams (2011, Figure 2)
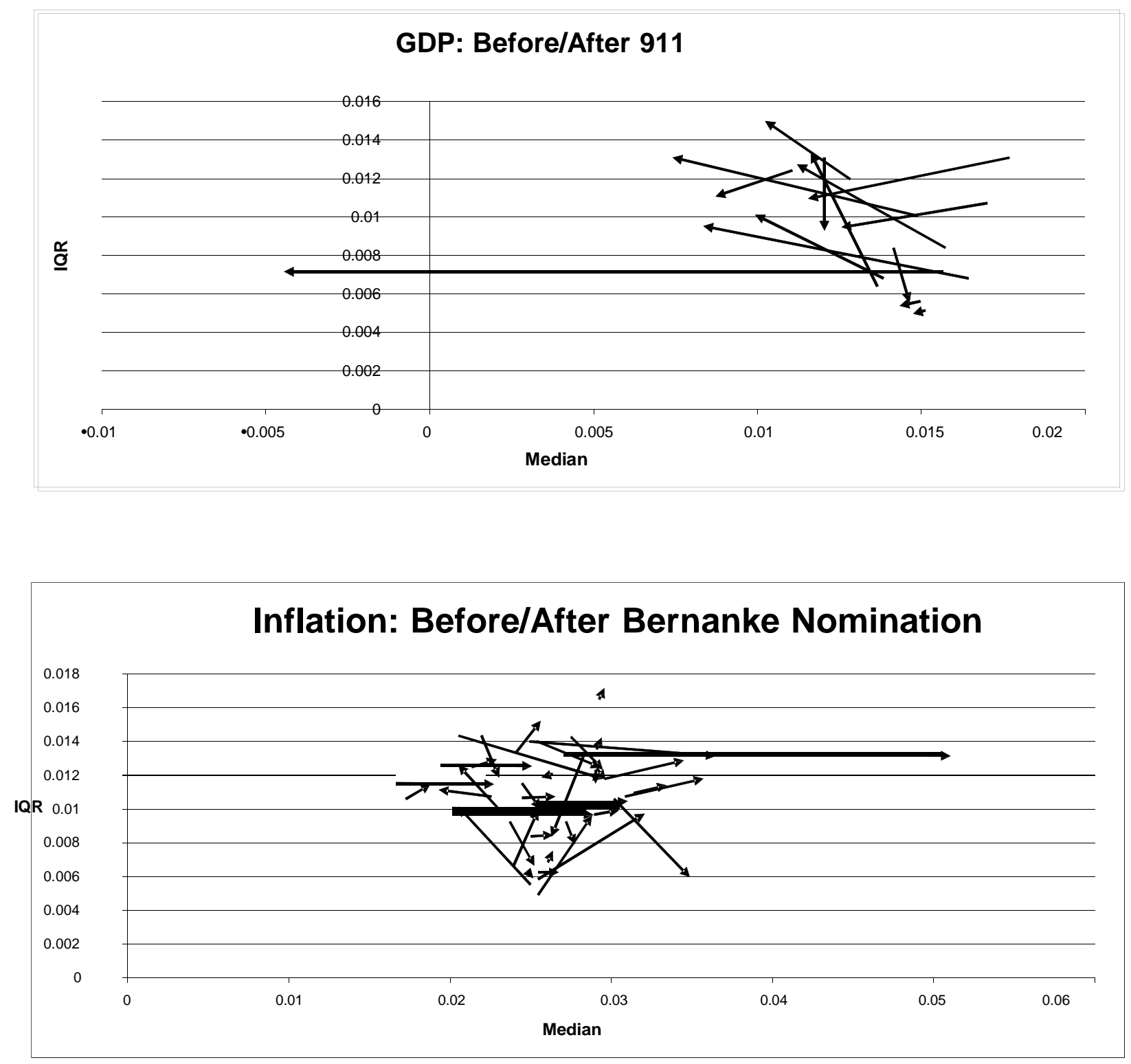